Document downloaded from:

http://hdl.handle.net/10251/52524

This paper must be cited as:

F. Payri; P. Olmeda; J. Martín; García Martínez, A. (2011). A complete OD thermodynamic predictive model for direct injection diesel engines. Applied Energy. 88:4632-4641. doi:10.1016/j.apenergy.2011.06.005.

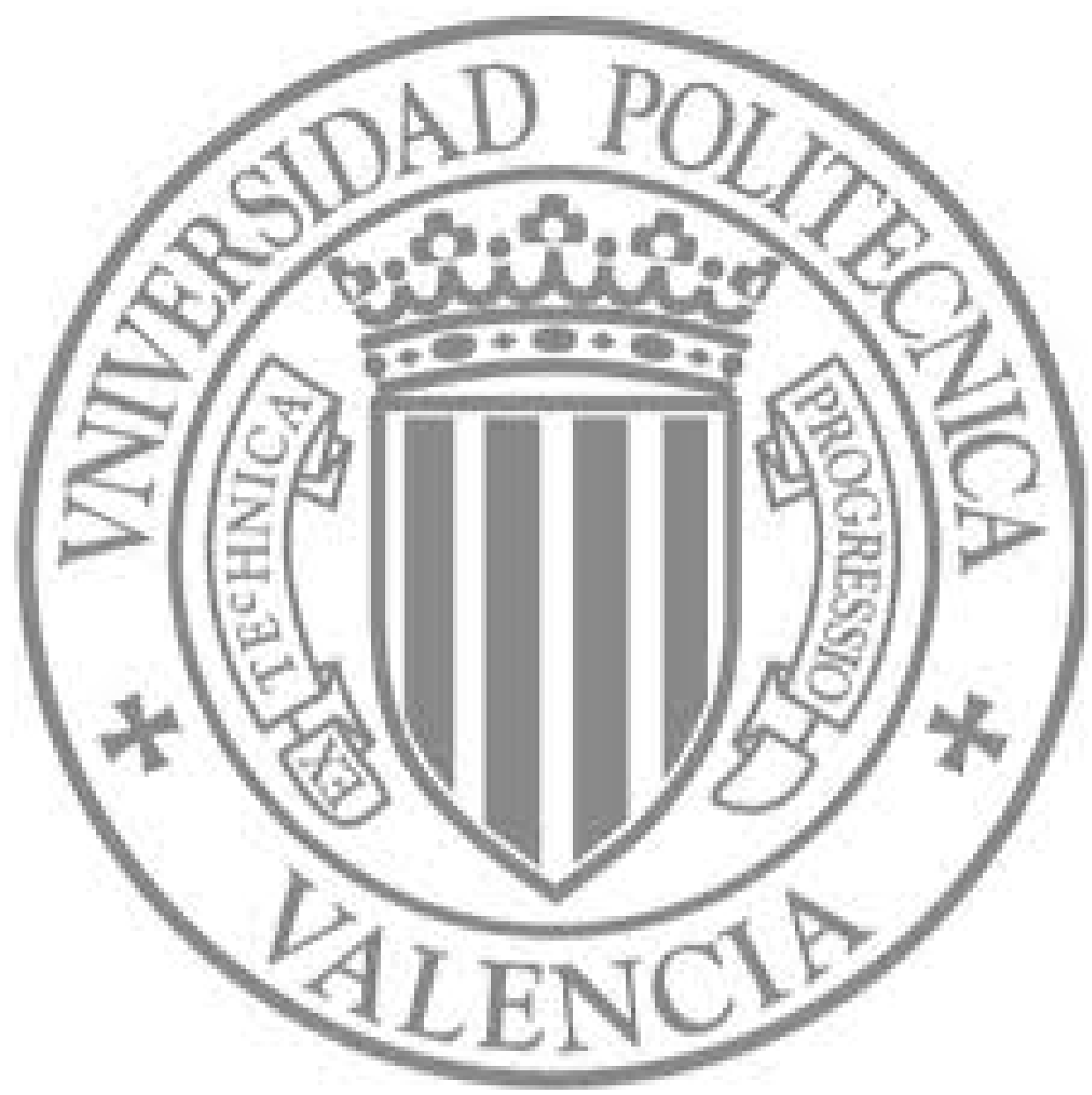

The final publication is available at

http://dx.doi.org/10.1016/j.apenergy.2011.06.005

Copyright Elsevier 


\title{
A complete 0D thermodynamic predictive model for Direct Injection Diesel engines
}

\author{
F. Payri, P. Olmeda, J. Martín*, A. García \\ CMT-Motores Térmicos, Universidad Politécnica de Valencia, Camino de Vera s/n. 46022 Valencia, \\ Spain
}

\begin{abstract}
Ideal models provide the simplest way to reproduce internal combustion engine (ICE) cycles, but usually they do not represent with sufficient accuracy the actual behaviour of an ICE. A suitable alternative for research and development applications is provided by zero-dimensional (0D) thermodynamic models. Such models are very useful to predict the instantaneous pressure and temperature in the combustion chamber, which in turn allow the prediction of engine operation characteristics. However, their simplifying hypotheses led in some cases to a leak of accuracy or a limited predictive capability.

This paper describes a 0D single-zone thermodynamic model that takes into account the heat transfer to the chamber walls, the blow-by leakage, the fuel injection and engine deformations, along with the instantaneous change of the gas properties. Special attention have been paid to the description of the specific sub-models that have been used for the calculation of the energy and mass equations terms. Also the procedures followed for the estimation of some mechanical and heat transfer parameters and the combustion model fitting is detailed. After the fitting, the model was validated in a large amount of operation points in a 4-cylinder 2-litre DI diesel engine, showing a good capability for accurate predictions of the gas state during the closed cycle and engine performance.
\end{abstract}

Keywords: real cycles, thermodynamic model, heat transfer, blow-by leakage, engine deformations

\footnotetext{
${ }^{*}$ Corresponding author. Tel.: +34 963877650; fax: +34 963877659

Email address: jaimardi@mot.upv.es (J. Mart'in )
} 


\section{Nomenclature}

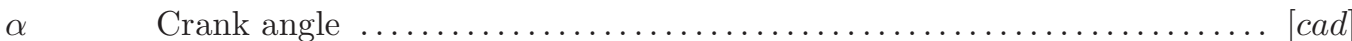

$c_{v} \quad$ Specific heat at constant volume $\ldots \ldots \ldots \ldots \ldots \ldots \ldots \ldots \ldots \ldots \ldots \ldots[\mathrm{J} / \mathrm{kg} \mathrm{K}]$

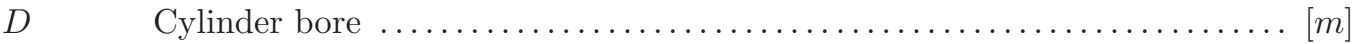

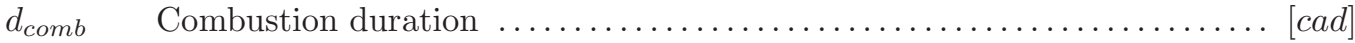

dHR Heat Released in a calculation step $\ldots \ldots \ldots \ldots \ldots \ldots \ldots \ldots \ldots \ldots \ldots \ldots \ldots \ldots \ldots \ldots \ldots \ldots$

EVO Exhaust Valve Opening

$F_{s} \quad$ Stoichiometric fuel-air equivalence ratio $\left.\ldots \ldots \ldots \ldots \ldots \ldots \ldots \ldots \ldots \ldots \ldots\right]$

HRF Cummulated Heat Release Fraction $\ldots \ldots \ldots \ldots \ldots \ldots \ldots \ldots \ldots \ldots \ldots \ldots \ldots[-]$

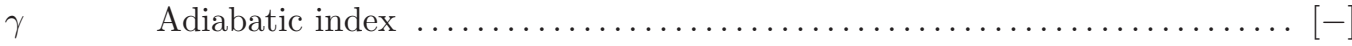

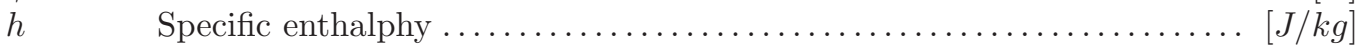

IVC

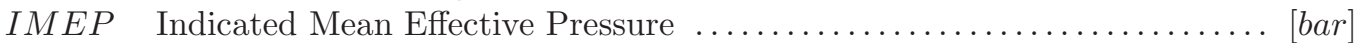

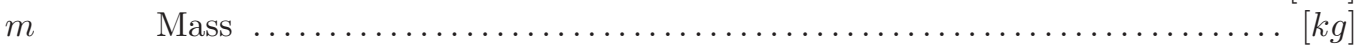

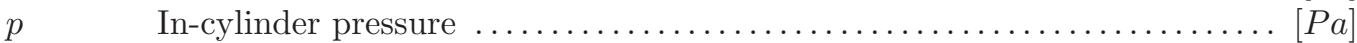

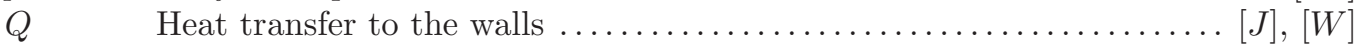

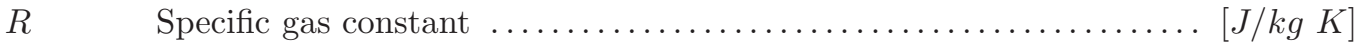

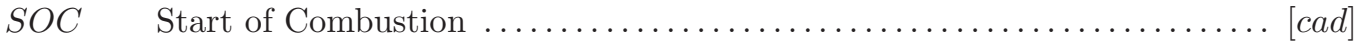

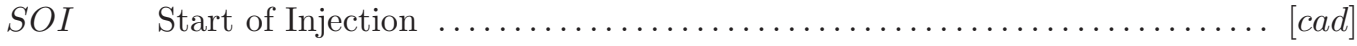

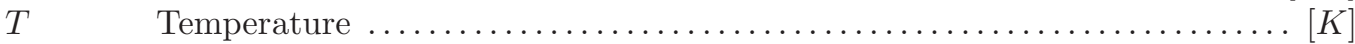

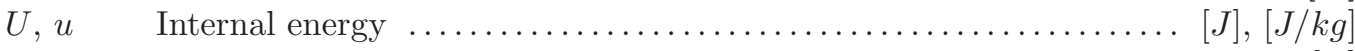

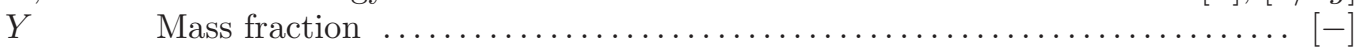


a Relative to the air

$b \quad$ Relative to the stoichiometric combustion products

bb Relative to the blow-by

$c \quad$ Relative to the gas mean properties in the chamber

cool Relative to coolant

exh Relative to exhaust conditions

$f \quad$ Relative to the fuel

$f, e v \quad$ Relative to the evaporated fuel

$f, g \quad$ Relative to the gaseous fuel

$f$, inj Relative to the liquid fuel at injection conditions

in Relative to inlet conditions

evap Relative to the evaporation

\section{Introduction}

Nowadays the main challenges in the internal combustion engines (ICE) consist on the reduction of fuel consumption and emissions. With this purpose different techniques have appeared to better optimize the combustion process: high pressure fuel injection systems [1], multiple injections [2], high boost pressure [3], EGR [4], variable valve timing [5], high swirl ratios [6], new clean fuels [7], .... Nevertheless, the great quantity of possible configurations for each engine condition as well as the necessity of shorter engine set up times, impose the use of predictive calculation models that allow to speed-up the search for the optimum configuration.

In this framework, ideal models represent the first approach to analyze the main trends of efficiency and engine power. Despite the claims by several researchers [8-10], it is generally accepted [11] that, due to their intrinsic limitations, do not represent with sufficient accuracy the behaviour of a current ICE.

To improve the ideal models performances, Bhattacharyya [12] included thermal and friction losses into an equivalent friction term in order to find the maximum power output varying compression ratio and cut-off ratio. On other hand, Akash [13] used a linear expression to estimate the heat added to the working fluid during combustion. Chen [14] conjugate previous works, i.e. he applied a linear expression for the heat transfer during combustion and estimate friction losses assuming that the friction losses force was a linear function of the velocity, as Angulo-Brown [15, 16] who used it for air-standard Otto cycle. Al-Sharki [17] included the temperature-dependent specific heats in order to improve previous works. Zhao [18] first included a new approach for determining the heat leakage level as a percentage of the fuel's chemical energy; and later on he included the specific heats dependence with temperature [19]. Other improvement in ideal model is carried out by [20] who used the Taylor model [21] to estimate the rate of heat loss. The most recent study [22] presents a diesel engine simulation where a dual Wiebe function [23] was used to model the heat release while the convective heat transfer coefficient is given by the Woschni model [24]. There are similar approaches to other cycles: Otto [25], Atkinson [26], Miller [27] and Dual [28]. 
In spite of the improvements performed in the ideal models by the cited authors and others, they have important assumptions to solve. A suitable alternative for research and development applications is provided by 0D thermodynamic models [11]. In these models, the mass and energy conservation equations are solved so that the instantaneous state of the gas inside the combustion chamber (pressure and temperature) is obtained. However, their simplifying hypotheses led in some cases to a leak of accuracy or a limited predictive capability. Their assumptions are related to the close system statement, i.e. the no consideration of blow-by through the piston rings and fuel addition, the use of correlations for air specific heat without considering the changes in the gas composition due to the fuel injection and chemical reactions that take place during the combustion process, i.e. the combustion products; and finally the consideration of a realistic heat release law. All this issues are dealt with in this work.

The objective of the present work is to develop a 0D single-zone thermodynamic model covering all the previous statements (the simulation of the rate of heat release law, heat transfer and gas properties sub-models as well as blow-by leakage and the fuel injection contributions to the diesel engine cycles) that have been partially covered by previous researchers. 0D models do not have spatial resolution, however they can consider one or more zones in the combustion chamber (mass and energy conservation equations are solved for each zone). In some applications, such as emissions prediction, or when the combustion details must be accounted for [29-31], it is imperative to consider more that one zone in order to obtain acceptable results. However, correctly calibrated and validated the proposed 0D single-zone model is suitable for the accurate calculation of the pressure evolution with the purpose of predicting engine performances and fuel economy or obtaining boundary conditions for specific combustion models with a high computational efficiency. Starting from Intake Valve Closing (IVC) conditions ( $p, m$ and $T$ ) the proposed model calculates the gas state up to the Exhaust Valve Opening (EVO) thus being a predictive tool that allows rapid parametric explorations of different engine operating conditions and geometric configurations.

\section{Thermodynamic model description}

In this section, the main hypothesis in which the thermodynamic model is based, the energy and mass balances as well as a description of sub-models required to calculate such balances are described.

\subsection{Basic hypothesis}

1. Uniform pressure in the chamber is assumed. This is normally assumed in combustion calculations because both fluid and flame velocities are much smaller than the sound speed [32].

2. Three species are considered: air, fuel vapour and stoichiometric combustion products. In a DI diesel engine operating with conventional combustion, during the mixing-controlled burning phase the flame is located at the stoichiometric fuel-air ratio region [33] and thus this hypothesis is quite realistic.

3. Perfect gas behaviour is assumed. This assumption is reasonable since negligible errors are committed as shown by Lapuerta et al. [35]. 
4. Specific heats depend on temperature and gas composition. This hypothesis is consistent with the two previous hypotheses.

5. Internal energy is calculated assuming mean uniform temperature in the chamber. This is perhaps the hardest hypothesis, as it affects the calculation of the internal energy of the gas. This can be specially important for the burned products at the beginning of the combustion. However, the error diminishes as the combustion progresses because dilution and heat transfer tend to make the temperature uniform.

6. Heat transfer to the chamber walls is considered. The fraction of the fuel energy lost by the heat transfer to the chamber walls depends on engine size (the larger the engine is the more adiabatic it is) and the operating conditions (the higher the load and the engine speed are, the more adiabatic it is). For a high speed DI diesel engine typical values range from $10 \%$ at full load and $4000 \mathrm{rpm}$ to $30 \%$ at low load and $1000 \mathrm{rpm}$. Therefore, consideration of heat transfer, depending on operating conditions, is necessary in order to obtain accurate predictions of indicated parameters or the thermodynamic state of the charge [36].

7. Blow-by leakage is considered. The blow-by mass flow is a good indicator of the integrity of the piston rings and lubricant. In normal operating conditions the blow-by mass flow is not important, and thus it is not usually measured. However, in small DI diesel engines (0.35 l of displacement) at low engine speeds, blow-by mass rates about $4 \%$ of the trapped mass have been measured; moreover, during the cold start it is usual to have more than $20 \%[37,38]$. It is thus advisable to consider this term in the mass and the energy balances, as it will be discussed below.

8. Fuel injection is considered. Althought the empirical combustion model that will be described later is not based on the injection rate, the consideration of the injected fuel is an important issue for both the mass and the energy balances. It has been checked that the error in the energy balance (that includes the temperature and gas properties errors due to the mass and composition errors) can reach a $7 \%$ in the case of rich fuel-air equivalence ratio. Thus the consideration of the injected mass is highly recommendable.

9. Engine deformation is considered. Usually, simple 0D models do not include engine deformations for the instantaneous volume calculation. However, the deformations of diesel engine, where pressure can easily reach 150 bar at the top dead center, can be higher than $2 \%$ at this point. Thus a simple deformation model will be used to estimate the real in-cylinder volume.

\subsection{Energy balance}

The energy and mass balance are solved between IVC and EVO, considering the combustion chamber as an open system because of the blow-by and the fuel injection. The main results are the instantaneous pressure and temperature. Accordingly to the hypotheses 1 and 5, no spatial resolution of the thermodynamic properties is considered.

The most general expression of the First Law for an open system is:

$$
\begin{aligned}
\mathrm{d} U_{c} & =-\mathrm{d} Q+\mathrm{d} W+h_{f, i n j} \mathrm{~d} m_{f, i n j}-h_{c} \mathrm{~d} m_{b b} \\
& =-\mathrm{d} Q-p \mathrm{~d} V+h_{f, i n j} \mathrm{~d} m_{f, i n j}-h_{c} \mathrm{~d} m_{b b}
\end{aligned}
$$


where $U_{c}$ is the internal energy of the charge, $Q$ is the heat transfer to the walls, $W$ is the work, $h_{f, i n j}$ is the specific enthalpy of the fuel at the injection conditions, $m_{f, i n j}$ is the injected fuel mass, $h_{c}$ is the specific enthalpy of the charge and $m_{b b}$ is the blow-by mass.

As the model considers only one zone in the chamber, a single gas phase is considered, and thus the injected fuel is taken into account in the mass and energy balances assuming that the evaporation takes place instantaneously. This assumption is realistic for main injections in which the time for atomization, heating and evaporation is negligible, whereas this is less realistic for early pilot injections. In order to describe the process rigorously it would be necessary to follow the fuel parcel during all its evolution from the injection conditions up to the mean chamber temperature. This would require the consideration of at least two zones (liquid and gaseous phases), and thus the model complication; however, it has been checked that minor improvements in the results would be obtained.

Accordingly to the previous comments, Eq. (1) may be written as

$$
\mathrm{d} U_{c}=-\mathrm{d} Q-p \mathrm{~d} V+h_{f, i n j} \cdot \mathrm{d} m_{f, e v}-h_{c} \mathrm{~d} m_{b b}
$$

where the evaporated fuel mass $m_{f, e v}$ has been considered instead of injected fuel mass $m_{f, i n j}$. Taking into account the hypothesis 2, the left-hand side of Eq. (2) can be expressed as:

$$
\begin{aligned}
\mathrm{d} U_{c}=\mathrm{d}\left(m_{c} u_{c}\right)= & \mathrm{d}\left(m_{a} u_{a}+m_{f, g} u_{f, g}+m_{b} u_{b}\right) \\
= & m_{a} \mathrm{~d} u_{a}+m_{f, g} \mathrm{~d} u_{f, g}+m_{b} \mathrm{~d} u_{b}+ \\
& +u_{a} \mathrm{~d} m_{a}+u_{f, g} \mathrm{~d} m_{f, g}+u_{b} \mathrm{~d} m_{b}
\end{aligned}
$$

where the subscripts $c, a, f, g$ and $b$ refer to chamber, air, gaseous fuel and stoichiometric burned products, respectively. The terms with $\mathrm{d} u_{a}, \mathrm{~d} u_{f, g}$ and $\mathrm{d} u_{b}$ in Eq. (3) correspond to the variation of internal sensible energy due to the change in the chamber temperature:

$$
\begin{aligned}
& m_{a} \mathrm{~d} u_{a}+m_{f, g} \mathrm{~d} u_{f, g}+m_{b} \mathrm{~d} u_{b}= \\
& =m_{a} c_{v, a} \mathrm{~d} T+m_{f, g} c_{v, f} \mathrm{~d} T+m_{b} c_{v, b} \mathrm{~d} T= \\
& =m_{c}\left(Y_{a} c_{v, a}+Y_{f} c_{v, f}+Y_{b} c_{v, b}\right) \mathrm{d} T=m_{c} c_{v, c} \mathrm{~d} T
\end{aligned}
$$

where $Y$ represents the fuel mass fraction. In Eq. (3), the terms with $\mathrm{d} m_{a}, \mathrm{~d} m_{f, g}$ and $\mathrm{d} m_{b}$ represent, respectively, the variation of the internal energy due to the composition change associated with combustion, the fuel injection and blow-by losses:

$$
\begin{aligned}
\mathrm{d} m_{a} & =-\mathrm{d} m_{a, b}-Y_{a} \mathrm{~d} m_{b b} \\
\mathrm{~d} m_{f, g} & =\mathrm{d} m_{f, e v}-\mathrm{d} m_{f, b}-Y_{f, g} \mathrm{~d} m_{b b} \\
\mathrm{~d} m_{b} & =\mathrm{d} m_{a, b}+\mathrm{d} m_{f, b}-Y_{b} \mathrm{~d} m_{b b}
\end{aligned}
$$

where $\mathrm{d} m_{a, b} \mathrm{y} \mathrm{d} m_{f, b}$ are the mass of air and fuel burned in stoichiometric conditions, so that

$$
\mathrm{d} m_{f, b}=F_{s} \cdot \mathrm{d} m_{a, b}
$$

Taking into account Eqs. (7) and (8), the variations of the air and fuel masses (Eqs. (5) and (6)) can be expressed in terms of the variation of the stoichiometric burned 
mass. Substituting into Eq. (3), taking into account Eq. (4), after some algebra Eq. (1) becomes:

$$
\begin{gathered}
{\left[u_{b}-\frac{u_{a}+u_{f, g} F_{e}}{F_{e}+1}\right] \cdot\left(\mathrm{d} m_{b}+Y_{b} \mathrm{~d} m_{b b}\right)=} \\
=-m_{c} c_{v, c} \mathrm{~d} T-\mathrm{d} Q-p \mathrm{~d} V+\left(h_{f, i n j}-u_{f, g}\right) \cdot \mathrm{d} m_{f, e v}-R_{c} T \mathrm{~d} m_{b b}
\end{gathered}
$$

where the first term in Eq. (9) is the heat released by combustion - dHR.

The negative sign before dHR is used for consistency with the sign criterion used for the heat transfer to the wall: positive means lost by the charge and negative supplied to the charge. In this way, dHR is positive and should be interpreted as the heat supplied to the gas as a result of combustion. If the negative sign had not been included, dHR would be the reaction energy (which would be negative since the internal energy of the combustion products is lower than that of the reactants). With this criterion, one may write:

$$
\mathrm{dHR}=m_{c} c_{v, c} \mathrm{~d} T+\mathrm{d} Q+p \mathrm{~d} V-\left(h_{f, i n j}-u_{f, g}\right) \cdot \mathrm{d} m_{f, e v}+R_{c} T \mathrm{~d} m_{b b}
$$

In Eq. (10) all the involved phenomena can be easily identified: at the left-hand side dHR is the heat released by combustion in a calculation step (the RoHR can be directly obtained by dividing $\mathrm{dHR}$ by the angle step, $\mathrm{RoHR}=\mathrm{dHR} / \mathrm{d} \alpha$ ), whereas the terms in the right-hand side are, respectively, the sensible internal energy of the gas, the heat transfer to the walls, the work done by the gas, the energy related to fuel injection, evaporation and heating, and the flow work associated with the blow-by leakage.

The fuel injection term can be also decomposed as follows:

$$
\begin{aligned}
h_{f, i n j}-u_{f, g}= & h_{f, l}\left(T_{i n j}\right)-u_{f, g}(T)= \\
= & {\left[h_{f, l}\left(T_{i n j}\right)-u_{f, l}\left(T_{i n j}\right)\right]-\left[u_{f, l}\left(T_{\text {evap }}\right)-u_{f, l}\left(T_{i n j}\right)\right]-} \\
& -\left[u_{f, g}\left(T_{\text {evap }}\right)-u_{f, l}\left(T_{\text {evap }}\right)\right]-\left[u_{f, g}(T)-u_{f, g}\left(T_{\text {evap }}\right)\right]
\end{aligned}
$$

where the temperature at which enthalpies and internal energies are evaluated has been indicated in brackets. The four terms in the right-hand side of Eq. (11) corresponds to:

- Specific flow work of the injected fuel

- Liquid fuel heating from the injection temperature $\left(T_{i n j}\right)$ up to the evaporation temperature $\left(T_{\text {evap }}\right)$

- Internal energy of vaporization

- Gaseous fuel heating from the vaporization temperature up to the mean gas temperature $\left(T_{c}\right)$.

To finish the description of the energy balance, it is necessary to remark that all the terms in Eq. (9) depend on different variables but all of them depends only on pressure and temperature. Thus Eq. (9) has two unknown variables and an additional equation is required to solve it: the equation of state. Accordingly with hypothesis 3 the ideal gas equation is used to close the equations system:

$$
p V=m R_{c} T
$$


Eqs. (9) and (12) are solved for each calculation step from IVC to EVO, providing instantaneous pressure and temperature as the main results. Along with them, other results are obtained of which those most important are: instantaneous mass and composition, heat flux to the walls, and indicated parameters (pressure, work, consumption, etc.).

The sub-models used for the calculation of each term of Eq. (9) are described in the section 2.4.

\subsection{Mass balance}

The trapped mass at IVC is the addition of the induced mass of fresh air $\left(m_{a}\right)$, the exhaust gas recirculation mass $\left(m_{E G R}\right)$ and the residual gas of the previous cycle $\left(m_{\text {res }}\right)$, to which the short-circuiting mass $\left(m_{s c}\right)$ during valve overlap (which normally can be neglected in a 4 stroke engine) is subtracted. All of them are model inputs. The incoming masses $m_{a}$ and $m_{E G R}$ are obtained from experimental measurements, whereas $m_{\text {res }}$ and $m_{s c}$ are calculated with a simple filling and emptying model such as that described in [39].

Starting from IVC, the model calculates the instantaneous change of the mass of each species (air, fuel and stoichiometric burned products) associated with blow-by, fuel injection and combustion. Therefore, both instantaneous gas mass and composition can be obtained. The instaneous blow-by and fuel injected models are described in 2.4.1 and 2.4 .2

In order to calculate the thermodynamic properties of the gas (see 2.4.3), it is necessary to know the instantaneous gas composition [40]. Taking into account the masses involved, the mass fraction of the burned products at EVO can be expressed as:

$$
\begin{aligned}
Y_{b, E V O} & =\frac{m_{f}+\frac{m_{f}}{F_{s}}+\left(m_{E G R}+m_{r e s}\right) \cdot Y_{b, E V O}-m_{s c} \cdot Y_{b, I V C}-m_{b b}\left(\frac{Y_{b, I V C}+Y_{b, E V O}}{2}\right)}{m_{a}+m_{f}+m_{E G R}+m_{r e s}-m_{s c}-m_{b b}} \\
& =\frac{1+\frac{1}{F_{s}}-Y_{b, I V C}\left(\frac{m_{s c}+m_{b b} / 2}{m_{f}}\right)}{1+\frac{1}{F}-\frac{m_{s c}+m_{b b} / 2}{m_{f}}}
\end{aligned}
$$

where the mean of IVC and EVO compositions has been assumed for the blow-by mass leakage. At IVC the composition can be expresed as:

$$
\begin{aligned}
Y_{b, I V C} & =\frac{m_{E G R} \cdot Y_{b, E V O}+m_{r e s} \cdot Y_{b, E V O}-m_{s c} \cdot Y_{b, I V C}}{m_{a}+m_{E G R}+m_{r e s}-m_{s c}} \\
& =\frac{Y_{b, E V O}}{1+\frac{m_{a}}{m_{E G R}+m_{r e s}}}
\end{aligned}
$$

Substitution of Eq. (14) into Eq. (13) gives $Y_{b, E V O}$ expressed in terms of known parameters:

$$
Y_{b, E V O}=\frac{1+\frac{1}{F_{s}}}{1+\frac{1}{F}-\left(\frac{m_{s c}+m_{b b} / 2}{m_{f}}\right) \frac{1}{1+\frac{m_{E G R}+m_{r e s}}{m_{a}}}}
$$


At any intermediate instant $i$ between IVC and EVO, the instantaneous mass fraction of burnt products can be written as a function of the heat release fraction (see section 2.4.4):

$$
Y_{b}=\frac{\left(m_{f}+\frac{m_{f}}{F_{s}}\right) \cdot \operatorname{HRF}+\left(m_{E G R}+m_{r e s}\right) \cdot Y_{b, E V O}-m_{s c} \cdot Y_{b, I V C}-\int_{I V C}^{i} Y_{b} \cdot d m_{b b}}{m_{a}+\int_{I V C}^{i} \mathrm{~d} m_{f}+m_{E G R}+m_{r e s}-m_{s c}-\int_{I V C}^{i} \mathrm{~d} m_{b b}}
$$

The unburnt gaseous fuel mass fraction at any intermediate instant can also be obtained as a function of the instantaneous heat release fraction:

$$
Y_{f}=\frac{\int_{I V C}^{i} m_{f}-m_{f} \cdot \mathrm{HRF}}{m_{a}+\int_{I V C}^{i} \mathrm{~d} m_{f}+m_{E G R}+m_{r e s}-m_{s c}-\int_{I V C}^{i} \mathrm{~d} m_{b b}}
$$

An hence the instantaneous air mass fraction is calculated as $Y_{a}=1-Y_{b}-Y_{f}$.

The fuel mass injected per cycle, $m_{f}$, is obtained from experimental measurements (along with $m_{a}$ and $\left.m_{E G R}\right)$. The instantaneous mass of evaporated fuel $\left(\mathrm{d} m_{f}\right)$ is obtained as described in paragraph 2.4.2.

\subsection{Sub-models description}

A detailed description of the sub-models used to calculate the different terms in Eq. (9) are included in the following section.

\subsubsection{Blow-by model}

The instantaneous mass flow of blow-by to the crankcase is estimated by means of the equation of an adiabatic nozzle as in [41]:

$$
\dot{m}_{b b}=c_{b b} A_{r e f} p \sqrt{\frac{x}{R_{c} T}}
$$

where $x=\frac{2 \gamma}{(\gamma-1)}\left[\left(\frac{p_{c r k}}{p}\right)^{\frac{2}{\gamma}}-\left(\frac{p_{c r k}}{p}\right)^{\frac{\gamma+1}{\gamma}}\right]$. The discharge coefficient of the nozzle, $c_{b b}$, was adjusted with experimental measurements so that the cumulated blow-by coincided with the actual flow, $A_{\text {ref }}$ is the reference section proposed by Hohenberg $[42]\left(3.5 \cdot 10^{-6} D\right)$ and $p_{c r k}$ is the crankcase pressure.

When the pressure ratio accomplishes:

$$
\frac{p_{c r k}}{p}<\left(\frac{2}{\gamma+1}\right)^{\frac{\gamma}{\gamma-1}}=\frac{p_{c r i t}}{p}
$$

sonic conditions is reached and then the nozzle flow must be calculated considering the critical pressure instead of the crankcase pressure. 


\subsubsection{Fuel injection model}

As it is justified later, the consideration of the fuel injection has an important effect on the mass balance, gas composition and energy balance and thus it must be considered to get accurate simulation results. However, as the rate of heat release (see section 2.4.4) contains the main combustion information the accuracy of the injection rate shape is not a critical issue, thus a square-shaped law is assumed for the fuel injection rate. It has been checked that consideration of a more realistic injection rate produces only minor improvements in the description of the thermodynamic evolution in the combustion chamber.

It must be born in mind that the model is not a predictive combustion model and thus it does not account for the real effect of the injection rate on the heat release. Such an effect should be taken into account with a physical combustion model such as that proposed by Arrègle et al. [43, 44]. However, this is out of the scope of this work.

\subsubsection{Gas properties model}

The thermodynamic properties of the gas are calculated in the following way:

$$
R_{c}=R_{a} \cdot Y_{a}+R_{f} \cdot Y_{f}+R_{b} \cdot Y_{b}
$$

$$
c_{v, c}=c_{v, a} \cdot Y_{a}+c_{v, f} \cdot Y_{f}+c_{v, b} \cdot Y_{b}
$$

where subscripts $c, a, f$ and $b$ refer to the mean properties of the chamber, air, fuel and stoichiometric burned products, respectively. $R_{a}, R_{f}$ and $R_{b}$ are the specific constants of each species, and the specific heats at constant volume, $c_{v, a}, c_{v, f}$ y $c_{v, b}$ are obtained of polynomial expressions as a function of the temperature [40].

\subsubsection{Heat release law model}

The most complex process to be considered when performing the energy balance is combustion. Different proposals can be found in literature for the modelling of this phenomenon, from the simplest heat release laws proposed by Wiebe [23] or Watson [45] to the considerably more complex phenomenological models proposed by Barba [46], Hiroyasu [29] or Arrègle et al. [43, 44].

As stated, the objective of the proposed model is not the prediction of the physical phenomena involved in the combustion process, but the provision of accurate thermodynamic conditions in the chamber. Therefore, following the proposal of Serrano et al. [47], a simple phenomenological model with several Wiebe functions have been used in order to describe the RoHR: in operating point with pilot injection, one Wiebe function $\left(W_{1}\right)$ is used to reproduce it, another three Wiebe functions $\left(W_{2}, W_{3}\right.$ and $\left.W_{4}\right)$ are always used to simulate the premixed, diffusion and late combustion phases respectively. Hence, the mathematical expression of the rate of heat release is:

$$
R o H R=\sum_{i=1}^{4}\left[\frac{C_{i}\left(m_{i}+1\right)}{d_{c o m b, i}}\left(\frac{\alpha-S O C_{i}}{d_{c o m b, i}}\right)^{m_{i}} e^{\left[-C_{i}\left(\frac{\alpha-S O C_{i}}{d_{c o m b}, i}\right)^{\left(m_{i}+1\right)}\right]} \cdot \beta_{i}\right]
$$

where $\alpha$ is the crank angle, $d_{c o m b, i}$ is the duration of the combustion phase $i$ (pilot, premixed, diffusion or late combustion), $S O C_{i}$ is the start of the combustion phase $i, \beta_{i}$ is the proportion of the combustion phase $i$ with respect to the whole combustion (hence its value varies between 0 and 1$), C_{i}$ is the completion parameter that is traditionally 
used to represent the combustion efficiency and $m_{i}$ is the shape parameter that controls the gradient of the combustion phase $i$.

The methods follow to fit the values of $d_{c o m b, i}, S O C_{i}, \beta_{i}$ and $m_{i}$ will be discussed later.

\subsubsection{Volume calculation model}

The instantaneous volume in the cylinder is calculated as the addition of combustion chamber volume, the instantaneous displaced volume and the deformation due to pressure and inertial forces:

$$
V=V_{c c}+V_{d, \text { inst }}+\Delta V_{p}+\Delta V_{i}
$$

where

$$
V_{c c}=\frac{V_{d}}{r_{c}-1}
$$

being $V_{d}$ the total displaced volume and $r_{c}$ the compression ratio. The instantaneous displaced volume $V_{d, \text { inst }}$ is calculated taking into account the engine geometry, including the piston eccentricity. The two deformation terms in Eq. (23) are based on a previous work [34]:

$$
\Delta V_{p}=k_{\text {def }} \cdot \frac{\pi D^{2}}{4} \cdot \frac{p}{E_{\text {steel }}} \cdot\left(\frac{D}{D_{p p}}\right)^{2} \cdot L_{0}
$$

$$
\Delta V_{i}=k_{\text {def }} \cdot \frac{m_{\text {alt }} \cdot a}{E_{\text {steel }}} \cdot\left(\frac{D}{D_{p p}}\right)^{2} \cdot L_{0}
$$

where $k_{\text {def }}$ is a deformation coefficient that is experimentally fitted using motoring tests, as described in section 3.1 (typical values range from 1 to 3 ), $E_{\text {steel }}=2.1 \cdot 10^{11} \mathrm{~N} / \mathrm{m}^{2}$ is the elasticity coefficient of the steel, $D_{p p}$ is the piston pin diameter, $m_{\text {alt }}$ is the mass with reciprocating motion, $a$ is the instantaneous piston acceleration and $L_{0}$ is a characteristic length defined as:

$$
L_{0}=h_{p i s}+L_{c}+\frac{S}{2}
$$

where $h_{p i s}$ is the distance from the piston pin axis to the top surface of the piston, $L_{c}$ is the connecting rod length and $S$ is the stroke.

\subsubsection{Heat transfer model}

Concerning the heat transfer to the combustion chamber walls, in motoring tests (or during compression stroke and after the end of combustion), this process is essentially governed by convection (even though gas radiation to the walls also occurs, in those conditions this mode of heat transfer is negligible in comparison with convection [48]). While combustion is taking place, additionally to convection there is also radiation from the gas and the soot particles formed. There is no agreement with respect to the fraction of the heat transfer that is transferred by radiation: Morel and Keribar [49] obtained values ranging from $4 \%$ to $20 \%$, whereas Heywood [11] states that this fraction can be higher than 20\%. Anyway, any accurate radiative model would require the calculation of the soot formed in the spray $[11,50]$, which is out of the scope of this work.

In the present model, a variation of the expression proposed by Woschni $[24,51]$ is used to calculate the heat transfer coefficient. However, several efforts have been done in order to improve the original model proposed by Woschni. As described in detail in 
two previous works $[52,53]$, the values of the constants in the model have been modified, and the way in which the swirl effect is considered is also different, so that more realistic predictions in direct injection Diesel engines can be achieved. Those improvements were performed by means of CFD calculations, as it is described in the cited references. The expression used for the heat transfer coefficient is:

$$
h=C D^{-0.2} p^{0.8} T^{-0.53}\left[C_{W 1} c_{m}+C_{W 2} c_{u}+C_{2} \frac{V_{d} T_{I V C}}{V_{I V C} p_{I V C}}\left(p-p_{0}\right)\right]^{0.8}
$$

where $C=0.12$ and $C_{2}=0.001, c_{m}$ is the mean piston speed, $c_{u}$ is the instantaneous tangential velocity of the gas in the chamber (see [52] for the details of the calculation), $C_{W 1}$ and $C_{W 2}$ are constants whose values are fitted (along with $k_{d e f}$ ) from motoring tests on a specific engine, and $p_{0}$ is the motoring pressure assuming polytropic evolution.

Finally, the calculation of the heat flux to the wall requires the estimation of the wall temperatures. A nodal model that calculates the mean temperature of the liner, piston and cylinder head temperatures is used [54, 55].

\section{Experimental study: adjustment and validation}

In the following section the adjustment process for the different models is described as well as the validation performed. The experimental measurements were carried out in a high speed direct injection diesel engine with 2.0-liter displacement. It is a currently in production engine produced by an European manufacturer. It is a four-cylinder turbocharged engine equipped with a common rail injection system. Its main characteristics are given in Table 1. The engine was directly coupled to an electric dyno. An AVL tests system collects the mean variables (acquired at a constant sample frequency of $100 \mathrm{~Hz}$ ) necessary for controlling the engine operating point and also for the combustion diagnosis. In-cylinder pressure was measured in one of the cylinders by means of a Kistler 6055B glow-plug piezoelectric transducer with a measurement range of 0-250 bar.

\subsection{Adjustment process}

Some of the models described in the previous section have a number of constants that have to be adjusted. In particular is is necessary to set the values of the heat transfer model constant $C_{W 1}, C_{W 2}$ (section 2.4.6) and the deformation model constant $k_{d e f}$ (section 2.4.5); also it is necessary to fit the values of the Wiebe constants in the combustion model described in section 2.4.4. The adjustment was done using experimental measurements obtained through a broad parametric study of the engine, both in motoring and combustion operation conditions as described below.

\subsubsection{Mechanical and heat transfer characterization}

The values of the constants $C_{W 1}, C_{W 2}$ and $k_{d e f}$ are fitted using experimental motoring tests performed on the engine to be modeled. The adjustment method is based on the sensitivity of the thermodynamic cycle to uncertainties in motoring conditions, as Lapuerta et al. studied $[56,57]$. In motoring conditions, dHR is zero and the heat transfer to the walls, dQ, can be solved in the energy balance Eq. (10), which provides an "experimental" measurement of the heat transfer based on in-cylinder pressure [57]. An equivalent analysis can be done by imposing the heat transfer of the Woschni-like 
model in Eq. (10), and then computing the error in dHR [56] (theoretically it should be zero in motoring conditions). The constant $k_{\text {def }}$ has a characteristic effect on the thermodynamic cycle (both in terms of heat transfer to the wall and the error in dHR) and the heat transfer calculated with the Woschni-like model depends on $C_{W 1}, C_{W 2}$. It is thus possible to adjust the real value of the uncertainties so that the "experimental" heat transfer to the walls coincides with the results of the Woschni-like model and thus the error in dHR is minimised.

The characterization procedure is performed on a set of motoring tests with the typical range of the main Diesel engine parameters as detailed in the Table 2. The results obtained from the fitting process are $C_{W 1}=1.95, C_{W 2}=1.15$ and $k_{d e f}=2.64$.

\subsubsection{Combustion model adjustment}

The values of parameters $d_{c o m b, i}, S O C_{i}, \beta_{i}$ and $m_{i}$ in equation 22 are obtained by fitting the rate of heat release to experimental ones obtained with the combustion analysis tool CALMEC [34]. With the aim of providing more generality to the mathematical Wiebe combustion model, phenomenological criteria proposed by Serrano et al. [47] was followed in order to diminish the number of parameters to fit:

$$
\begin{aligned}
& \beta_{4}=1-\beta_{1}-\beta_{2}-\beta_{3} \\
& \beta_{1}>0, \beta_{2}>0, \beta_{3}>0 \\
& C_{i}=6.9 \forall i \\
& S O C_{1}<S O C_{2}<S O C_{3} \\
& S O C_{3}=S O C_{4} \\
& d_{c o m b, 2}<25 \mathrm{cad} \\
& d_{c o m b, 4}=130 \mathrm{cad} \\
& m_{i}>0 \forall i \\
& m_{2}=0.8
\end{aligned}
$$

The value of the completion parameter $C_{i}$ is 6.9 so that the percentage of energy released within the combustion duration is $99.9 \%$. This simplifications has enabled to reduce the number of adjusting parameters from 20 to 12. The rest of parameters were adjusted in 25 steady operating points (at different speed and loads) distributed in the complete engine map described in Table 3 . The operating points used for the model fitting are one half of the complete experimental matrix while the other half is aimed to validate the experimental results in the following section. The Levenberg-Marquardt algorithm $[58,59]$ was used to perform the parameters fitting.

\subsection{Validation of results}

For the model validation the complementary operating points to that used for the model fitting were used. Both fitting and validation operating point are equally distributed in the engine map, thus the values of the combustion model parameters in the validation operating points were interpolated from values obtained in the fitted operating points, as described in the previous section.

Figs. 1, 2 and 3 show the evolution of in-cylinder pressure, heat release for three different test points with a single injection (Fig. 3), a multiple injection (Fig. 2), both without EGR, and a case with EGR and two injections (Fig. 1), respectively. As can be seen, the agreement between measured and predicted heat release laws and cylinder traces is good. Ignition delay as well as premixed and diffusion combustion phases are well predicted. 
To illustrate the general behaviour of the model, Figs. 4, 5 and 6 show the maximum in-cylinder pressure, the pressure at exhaust valve opening and indicated mean effective pressure for all operating points used for both the model adjustment and model validation. The maximum pressure is a good parameter to account the performance of the model during the compression and the first stage of the combustion, similarly, the pressure at the EVO is a good indicator of the model behaviour during the last part of the combustion and expansion. Finally, the IMEP is the key parameter in all engine analysis and summarises well the general accuracy of the model. As can be seen in the stated figures, once the different models are adjusted using a first series of experimental tests ("Model fitting" in the figure legends), it is confirmed that the predictive character of the proposed tool is good ("Model validation" in the figure legends). In fact, the global error is just slightly higher in the validation tests. The difference can be attributed to the rate of heat release simulation; if a more accurate combustion model was used, the results would improve.

From the practical point of view, to get accurate results in agreement with experimental values is the key issue of a predictive model. However, it is also interesting to estimate which is the contribution of each submodel to the global accuracy to identify the main phenomena. With this purpose a short parametric study was performed. Its objective is to analyse the sensitivity of the results to different parameters included in the proposed submodels and its comparison with the effect of usual engine and operating parameters (compression ratio and injection timing). Six parameters were separately modified: blow-by rate, the constants of the heat transfer model $\left(C_{W 1}\right.$ and $\left.C_{W 2}\right), k_{d e f}$, compression ratio and start of injection (SOI), also the effect of including the injection rate was considered. A mean load (imep=12.5 bar) and mean engine speed (2000 rpm) operating point was used for the study. For each parameter (except fuel injection) three values were assumed as shown in Table 4 . The effect of the injected fuel was considered by means of the cycle simulation with and without including this term (in both the cases the rate of heat release was considered). The parameter variation ranges were set according to realistic experimental and modelled results in real engines. Although it is difficult to ensure the coherence of the variation of such different parameters, it was checked that the result sensitivity is almost linear and thus it is easy to extrapolate if different parameter range were considered. The values of $C_{W 1}$ and $C_{W 2}$ were changed simultaneously; the blow-by percentage is referred to trapped mass at IVC. The effect of each parameter variation on indicated pressure and maximum pressure are shown in Fig. 7.

The global trends obtained can be easily justified as follows. If no injection fuel is included the cooling effect of the evaporation is not taken into account and the specific heat of the gas in the chamber will be underestimated as the specific heat of the fuel is higher than those of the air and burnt products, thus higher imep and maximum pressures are obtained. The effect of advancing the SOI will produce a higher pressure peak and also a slightly higher imep value due to the change in the indicated diagram. The increase of the heat transfer parameter leads to higher heat losses and thus both imep and pressure peak diminish. If the engine deformation increases, the real compression ratio will diminish and lower in-cylinder pressures will be reached, thus diminishing the indicated performance of the engine. Similar conclusion can be stated if a higher blow-by leakage is considered. Finally, to increase the compression ratio has the opposite effect than the deformations: the higher $r_{c}$ is the higher the peak pressure and imep are due 
to the change in the instantaneous volume and indicated cycle.

At this point it is interesting to highly that the most influencing parameters for the imep prediction are the heat transfer, the blow-by leakage and the fuel injection and all of them are more important that the variation of the compression ratio or SOI. The heat transfer coefficients $C_{W 1}$ and $C_{W 2}$ have an important effect on the engine performance as they affects directly the heat transfer. It can be stated that if no heat transfer were considered, the error in the imep prediction is similar to varying the compression ratio about two points or modifying the SOI 3 cad. Concerning the blow-by, even if a lower leakage of about $2 \%$ (which is completely normal in real engines) is considered, its effects is higher than changing one point the compression ratio and similar to change 2 cad the SOI. Similar importance has the consideration of the injected fuel. Regarding the peak pressure sensitivity, the relative effect of these three parameters (fuel injection, heat transfer coefficients and blow-by) is not so big as in the case of imep, anyway they have a similar weight than compression ratio or SOI. In this case it is also clear that the deformation has an important effect similar to blow-by or fuel injection.

From this comments it is easy to conclude that all the described specific submodels are important to account for the corresponding phenomena, and if one or several of them were not included, the accuracy of the predictions shown in Figs. 4, 5 and 6 would be clearly worse.

\section{Conclusions}

In the proposed 0D thermodynamic model, the mass and energy conservation equations are solved in order to obtain the instantaneous gas state in the combustion chamber. A detailed description of the sub-models used for the calculation of each term appearing in the energy balance has been provided. In particular, specific sub-models to reproduce the blow-by leakage, the chamber deformation due to pressure and inertial efforts, the heat transfer to the chamber walls and the fuel injection have been presented.

Some constants in the stated sub-models needed to be adjusted and a thermodynamicbased procedure has been described in short. Also the combustion heat release laws needed to be estimated so that the model could have accurate predictive capability. The methodology followed is based on the fitting of several Wiebe function and allowed to estimate the rate of heat release in all the engine operating points.

Once the model adjusted, it has shown to be able to accurately reproduce the incylinder pressure evolution in a complete matrix of combustion tests in a DI Diesel engine.

Finally, it has been justified the necessity of including the proposed submodels for accurate prediction of the engine performance and it has been quantified the error in the simulation results if such submodel were not included.

\section{Acknowledgements}

The authors thank the Universidad Politécnica de Valencia (PAID-06-09) and Generalitat Valenciana (GV/2010/045) for its valuable support to this work and the referees for their worthy comments. 


\section{References}

[1] Wang X, Huang Z, Zhang W, Kuti OA, Nishida K. Effects of ultra-high injection pressure and micro-hole nozzle on flame structure and soot formation of impinging diesel spray. Appl Ener 2011;88:1620-1628.

[2] Park SH, Yoon SH, Lee CS. Effects of multiple-injection strategies on overall spray behavior, combustion, and emissions reduction characteristics of biodiesel fuel. Appl Ener 2011;88:88-98

[3] Al-Hinti I, Samhouri M, Al-Ghandoor A, Sakhrieh A. The effect of boost pressure on the performance characteristics of a diesel engine: A neuro-fuzzy approach. Appl Ener 2009;86:113-121

[4] Fontana G, Galloni E. Experimental analysis of a spark-ignition engine using exhaust gas recircle at WOT operation. Appl Energy 2010;87:218793.

[5] Fontana G and Galloni E. Variable valve timing for fuel economy improvement in a small sparkignition engine. Appl Energy 2009;86:96105.

[6] Prasad BVVSU, Sharma CS, Anand TNC, Ravikrishna RV. High swirl-inducing piston bowls in small diesel engines for emission reduction. Appl Energy (2011), doi:10.1016/j.apenergy.2010.12.068

[7] Kegl B. Influence of biodiesel on engine combustion and emission characteristics. Appl Energy 2011;88:1803-1812

[8] Hou SS. Comparison of performances of air standard Atkinson and Otto cycles with heat transfer considerations. Energ Convers Manage 2007;48:1683-1690.

[9] Lin JC, Hou SS. Performance analysis of an air-standard Miller cycle with considerations of heat loss as a percentage of fuel's energy, friction and variable specific heats of working fluid. Int J Therm Sci 2008;47:182-191.

[10] Ge YL, Chen LG, Sun FR, Wu C. Performance of Diesel cycle with heat transfer, friction and variable specific heats of working fluid. J Energy Inst 2007;80:239-242.

[11] Heywood, J.B. Internal combustion engine fundamentals. New York: McGraw-Hill; 1988.

[12] Bhattacharyya S. Optimizing an irreversible Diesel cycle - Fine tuning of compression ratio and cut-off ratio. Energ Convers Manage 2000;41:847-854.

[13] Akash BA. Effect of heat transfer on the performance of an air-standard diesel cycle. Int Commun Heat Mass 2001;28:87-95.

[14] Chen LG, Lin JX, Luo J, Sun FR, Wu C. Friction effect on the characteristic performance of Diesel engines. Int J Ener Res 2002;26:965-971.

[15] Angulo-Brown F, Fernandez-Betanzos J, Diaz-Pico CA. Compression ratio of an optimized Ottocycle model. Eur J Phys 1994;15:38-42.

[16] Angulo-Brown F, Rocha-Martinez JA, Navarrete-Gonzalez TD. A non-endoreversible Otto cycle model: improving power output and efficiency. J Phys D Appl Phys 1996;29:80-83.

[17] Al-Sarkhi A, Jaber JO, Abu-Qudais M, Probert SD. Effects of friction and temperature-dependent specific-heat of the working fluid on the performance of a Diesel-engine. Appl Ener 2006;83:153-165.

[18] Zhao YR, Lin BH, Zhang Y, Chen JC. Performance analysis and parametric optimum design of an irreversible Diesel heat engine. Energ Convers Manage 2006;47:3383-3392.

[19] Zhao YR, Chen JC. Optimum performance analysis of an irreversible Diesel heat engine affected by variable heat capacities of working fluid. Energ Convers Manage 2007;48:2595-2603.

[20] Al-Hinti I, Akash B, Abu-Nada E, Al-Sarkhi A. Performance analysis of air-standard Diesel cycle using an alternative irreversible heat transfer approach. Energ Convers Manage 2008;49:3301-3304.

[21] Taylor CF, Toong TY. Heat transfer in internal combustion engines. ASME paper 57-HT 17, 1957.

[22] Sakhrieh A, Abu-Nada E, Al-Hinti I, Al-Ghandoor A, Akash B. Computational thermodynamic analysis of compression ignition engine. Int Commun Heat Mass 2010;37:299-303.

[23] Wiebe I. Halbempirische formel fur die Verbrennungs-Geschwindigkeit. Verlag der akadimie der Wissenschaften der Vd SSR, Moscow, 1956.

[24] Woschni G. A universally applicable equation for the instantaneous heat transfer coefficient in the internal combustion engine, SAE Paper 670931, 1967.

[25] Abu-Nada E, Akash B, Al-Hinti I, Al-Sarkhi A. Performance of a spark ignition engine under the effect of friction using a gas mixture model J Energy Inst 2009;82:197-205.

[26] Ebrahimi R. Effects of mean piston speed, equivalence ratio and cylinder wall temperature on performance of an Atkinson engine. Mathematical and Computer Modelling 2011;53:12891297.

[27] Lin JC, Hou SS. Performance analysis of an air-standard Miller cycle with considerations of heat loss as a percentage of fuel's energy, friction and variable specific heats of working fluid. Int $\mathrm{J}$ Therm Sci 2008;47:182-191. 
[28] Ozsoysal OA. Effects of combustion efficiency on a Dual cycle. Energ Convers Manage 2009;50:2400-2406.

[29] Hiroyasu H, Kadota T, Arai M. Development and use of a spray combustion modelling to predict Diesel engine efficiency and pollutants emissions (part 1). Bulletin of the JSME 1983;26:569-575.

[30] Egnell R. Combustion diagnostics by means of multizone heat release analysis and NO calculation. SAE Paper 981424, 1998.

[31] Rakopoulos CD, Rakopoulos DC, Giacoumis EG, Kyritsis DC. Validation and sensitivity analysis of a two zone Diesel engine model for combustion and emissions prediction. Energ Convers Manage 2004;45:1471-1495.

[32] Williams F. Combustion theory. The Benjamin/Cummings Publishing Co., 1685.

[33] Faeth GM. Spray combustion fenomena. Twenty-Sixth Symposium (International) on Combustion. The combustion Institute, pp. 1593-1612.

[34] Payri F, Molina S, Martín J, Armas O. Influence of measurement errors and estimated parameters on combustion diagnosis. Appl Therm Eng 2006;26:226-236.

[35] Lapuerta M, Ballesteros R, Agudelo JR. Effect of the gas state equation on the thermodynamic diagnostic of diesel combustion. Appl Therm Eng 2006;26:1492-1499.

[36] Rakopoulos CD, Kosmadakis GM, Pariotis EG. Critical evaluation of current heat transfer models used in CFD in-cylinder engine simulations and establishment of a comprehensive wall-function formulation. Appl Ener 2010;87:1612-1630.

[37] Payri F, Broath A, Serrano JR, Rodriguez LF, Esmoris A. A Study of the potential of intake air heating in automotive DI Diesel engines. SAE Paper 2006-01-1233, 2006.

[38] Rakopoulos CD, Kosmadakis GM, Dimaratos AM, Pariotis EG. Investigating the effect of crevice flow on internal combustion engines using a new simple crevice model implemented in a CFD code. Appl Ener 2011;88:111126.

[39] Payri F, Galindo J, Martín J, Arnau FJ. A simple model for predicting the trapped mass in a DI Diesel engine. SAE Paper 2007-01-0494, 2007.

[40] Lapuerta M, Armas O, Hernández JJ. Diagnosis of DI Diesel combustion from in-cylinder pressure signal by estimation of mean thermodynamic properties of the gas. Appl Therm Eng 1999;19:513529 .

[41] E. Abdi Aghdam and MM Kabir. Validation of a blowby model using experimental results in motoring condition with the change of compression ratio and engine speed. Exp Therm Fluid Sci 2010;34:197-209.

[42] Hohenberg G. Definition und Eigenschaften des thermodynamischen Verlustwinkels von Kolbenmaschinen. Automobil-Industrie 1976;4:15-21.

[43] Arrègle J, López JJ, García JM, Fenollosa C. Development of a zero-dimensional Diesel combustion model. Part 1: analysis of the quasi-steady diffusion combustion phase. Appl Therm Eng 2003;23:1301-1317.

[44] Arrègle J, López JJ, García JM, Fenollosa C. Development of a zero-dimensional Diesel combustion model. Part 1: analysis of the transient initial and final diffusion combustion phases. Appl Therm Eng 2003;23:1319-1331.

[45] Watson N, Pilley AD, Marzouk M. A combustion correlation for Diesel engine simulation. SAE Paper 800029, 1980.

[46] Barba C, Burkhardt C, Boulouchos K, Bargende M. A phenomenological combustion model for heat release rate prediction in high-speed DI Diesel engines with common rail injection. SAE Paper 2001-01-2933, 2001.

[47] Serrano JR, Climent H, Guardiola C, Piqueras P. Methodology for characterisation and simulation of turbocharged diesel engines combustion during transient operation. Part 2: Phenomenological combustion simulation. Appl Therm Eng 2009;29:150158.

[48] Annand WJD. Heat transfer in the cylinders of reciprocating internal combustion engines. P I Mech Eng 1963;177:973-990.

[49] Morel T. and Keribar R. Heat radiation in DI Diesel engines. SAE Paper 860445, 1986.

[50] Dec J.E. A conceptual model of DI Diesel combustion based on lasersheet imaging. SAE Paper 970873, 1997.

[51] Woschni G. Die Berechnung der Wandverluste und der thermischen Belastung der Bauteile von Dieselmotoren. MTZ 31/12, 1970 pp. 491-499.

[52] Payri F, Margot X, Gil A, Martín J. Computational study of the heat transfer to the walls of a DI Diesel engine. SAE Paper 2005-01-0210, 2005.

[53] Payri F, Margot X, Gil A, Martín J. Prediction of heat transfer to the walls in DI Diesel engines. Proceedings of the 2nd EACC, 2005. 
[54] Torregrosa AJ, Olmeda P, Martín J, Romero C. A Tool for Predicting the Thermal Performance of a Diesel Engine. Heat Transfer Eng 2011; doi 10.1080/01457632.2011.548639.

[55] Torregrosa AJ, Broatch A, Olmeda P, Martín J. A contribution to film coefficient estimation in piston cooling galleries. Exp Therm Fluid Sci 2010;34:142-151.

[56] Lapuerta M, Armas O, Bermúdez V. Sensitivity of Diesel engine thermodynamic cycle calculation to measurement errors and estimated parameters. Appl Therm Eng 2000;20:843-861.

[57] Lapuerta M, Armas O, Molina S. Study of the compression cycle of a reciprocating engine through the polytropic coefficient. Appl Therm Eng 2003;23:313-323.

[58] Levenberg K. A method for the solution of certain non-linear problems in least squares. The Quarterly of Applied Mathematics 1944;2:164168.

[59] Marquardt D. An algorithm for least-squares estimation of nonlinear parameters. SIAM Journal of Applied Mathematics 1963;11:431441. 


\section{List of figures}

Fig. 1. Experimental and simulated RoHR and pressure at $2000 \mathrm{rpm}, 80 \mathrm{Nm}$ (25\% load), $15 \%$ EGR and 2 injections.

Fig. 2. Experimental and simulated RoHR and pressure at $3000 \mathrm{rpm}, 280 \mathrm{Nm}(100 \%$ load) and 2 injections.

Fig. 3. Experimental and simulated RoHR and pressure at $4000 \mathrm{rpm}, 120 \mathrm{Nm}(50 \%$ load) and single injection.

Fig. 4. Experimental and simulated maximum pressure.

Fig. 5. Experimental and simulated pressure at the exhaust valve opening.

Fig. 6. Experimental and simulated indicated mean effective pressure.

Fig. 7. Effect of the parameters on imep and maximum pressure. 


\section{${ }_{634}$ List of tables}

635

${ }_{636}$ Table 1. Engine main characteristics.

${ }_{637}$ Table 2. Motoring tests.

${ }_{638}$ Table 3. Combustion tests.

${ }_{639}$ Table 4. Parameters variation.

640

Table 1: Engine main characteristics

\begin{tabular}{lcc}
\hline Displaced volume & 2.0 & {$[l]$} \\
Cylinders & 4 & \\
Bore & 85 & {$[\mathrm{~mm}]$} \\
Stroke & 88 & {$[\mathrm{~mm}]$} \\
Connecting rod length & 145 & {$[\mathrm{~mm}]$} \\
Compression ratio & 17.8 & \\
Maximum power & 93 & {$[\mathrm{~kW}]$} \\
\hline
\end{tabular}


Table 2: Motoring tests.

\begin{tabular}{lccccc} 
& 1 & 2 & 3 & 4 & Units \\
\hline Speed & 1000 & 2000 & 3000 & 4000 & {$[\mathrm{rpm}]$} \\
Inlet pressure & 1026 & 1166 & 1129 & 1190 & {$[\mathrm{mbar}]$} \\
Inlet temperature & 36 & 49 & 49 & 56 & {$\left[{ }^{\circ} \mathrm{C}\right]$} \\
Exhaust pressure & 1115 & 1720 & 1620 & 1841 & {$[\mathrm{mbar}]$} \\
Exhaust temperature & 32 & 31 & 32 & 32 & {$\left[{ }^{\circ} \mathrm{C}\right]$} \\
\hline
\end{tabular}


Table 3: Combustion tests.

\begin{tabular}{lcc}
\hline Speed & $1000-4500($ steps of 500$)$ & {$[\mathrm{rpm}]$} \\
Load & $13-100$ & {$[\%]$} \\
Torque & $40-320($ steps of 40$)$ & {$[\mathrm{Nm}]$} \\
EGR & $0-35$ & {$[\%]$} \\
Rail pressure & $325-1600$ & {$[\mathrm{bar}]$} \\
Injections & $1-2$ & {$[-]$} \\
\hline
\end{tabular}




\begin{tabular}{cccc} 
Table 4: & \multicolumn{3}{c}{$\begin{array}{c}\text { Parameters variation. } \\
\end{array}$} \\
\cline { 2 - 4 } & 1 & 2 & 3 \\
\hline$m_{b b}$ & $0 \%$ & $2 \%$ & $4 \%$ \\
$C_{W 1}$ & 0.85 & 1.7 & 2.55 \\
$C_{W 2}$ & 0.5 & 1 & 1.5 \\
$k_{d e f}$ & 0 & 2 & 4 \\
$r_{c}$ & 15.3 & 16.3 & 17.3 \\
SOI & -2.4 & -3.4 & -4.4 \\
\hline
\end{tabular}




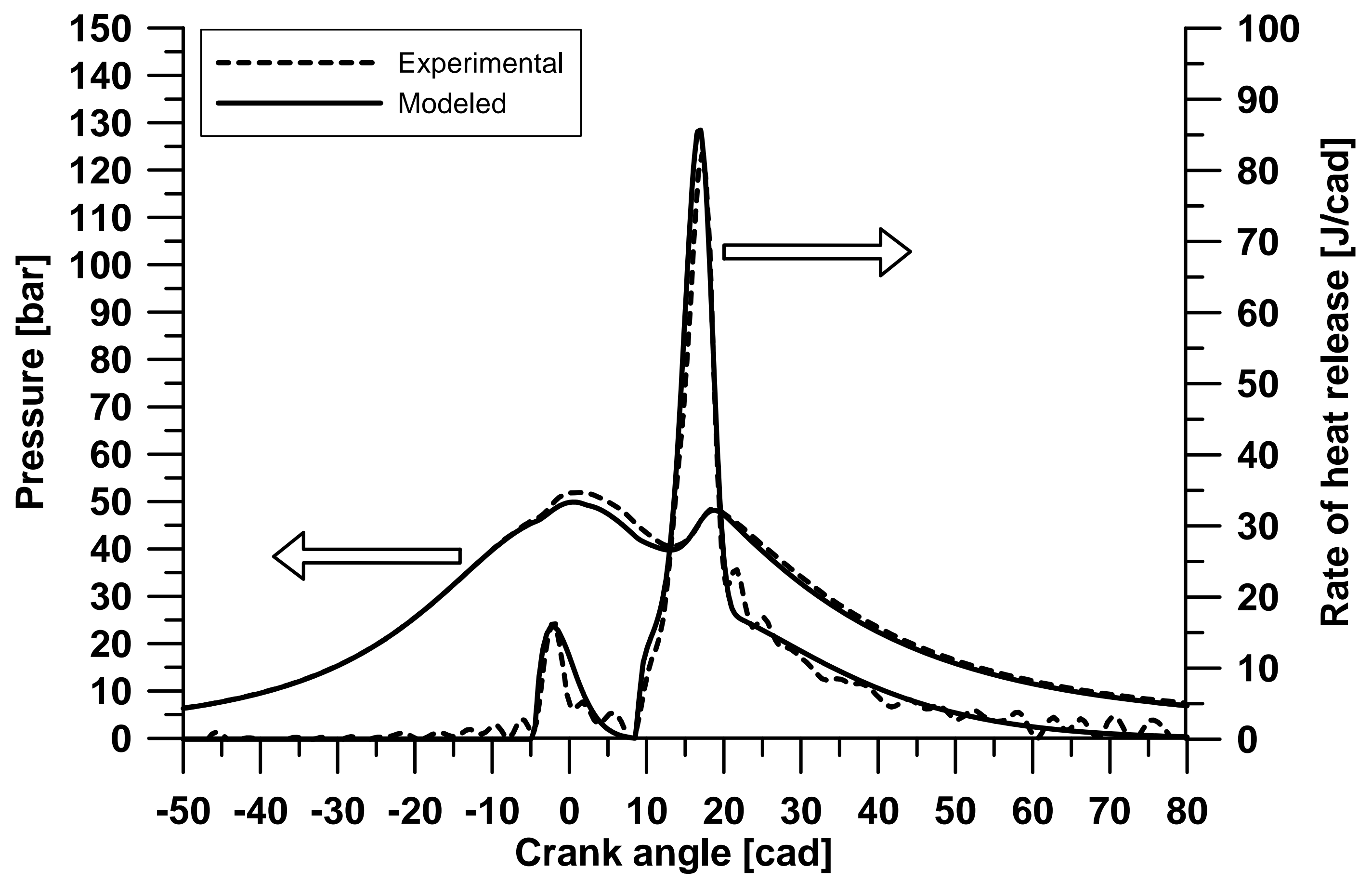




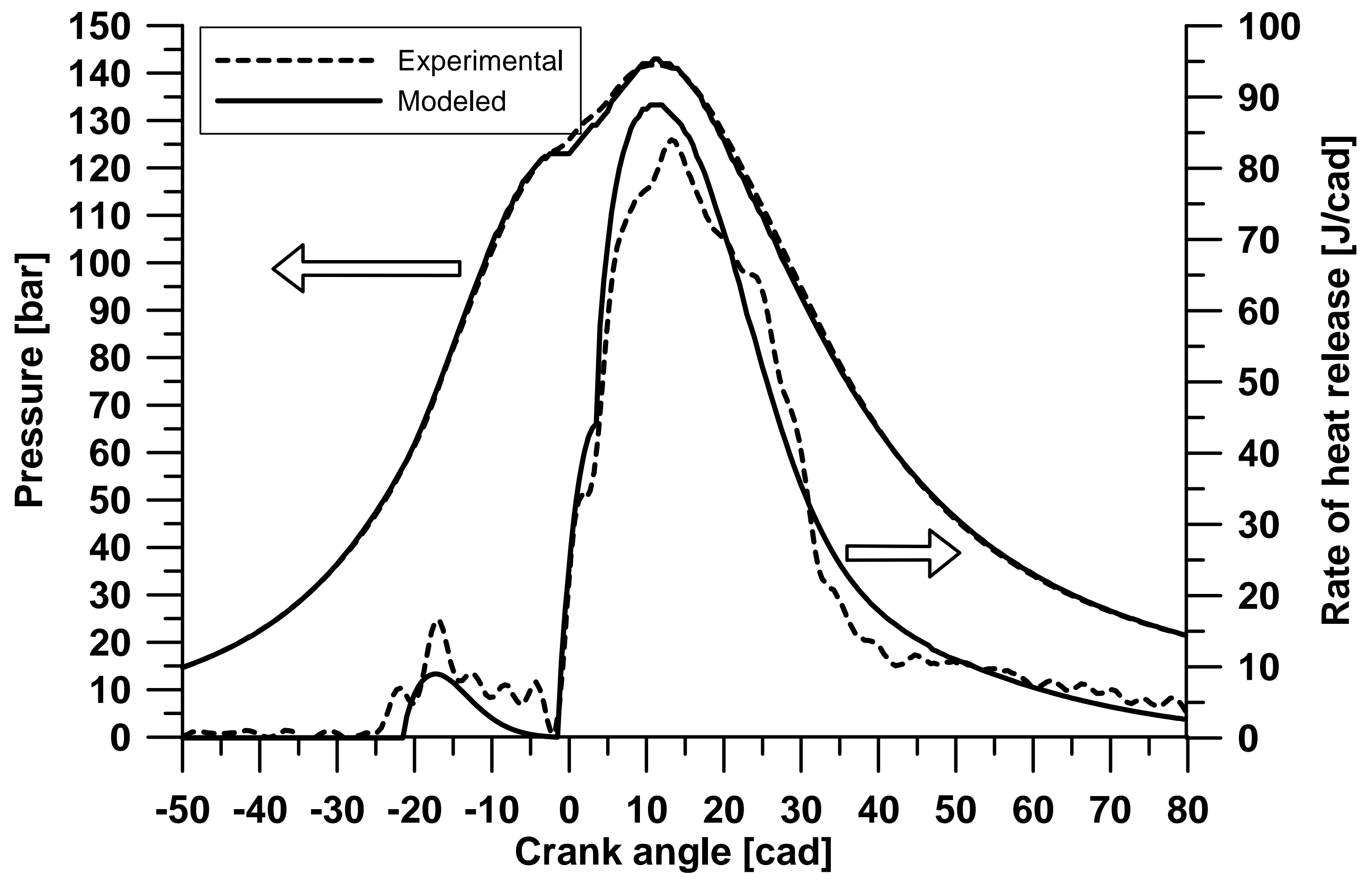




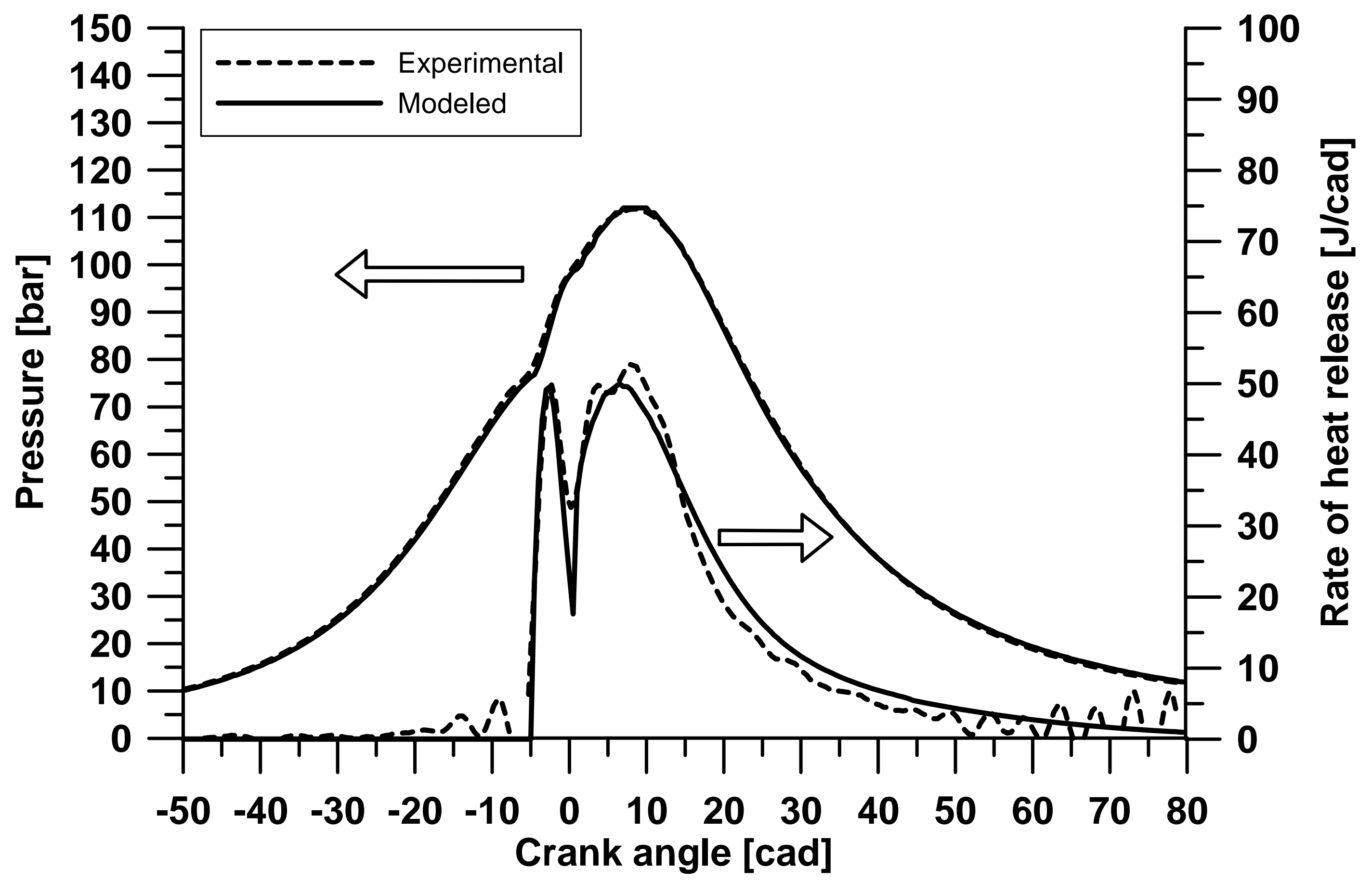




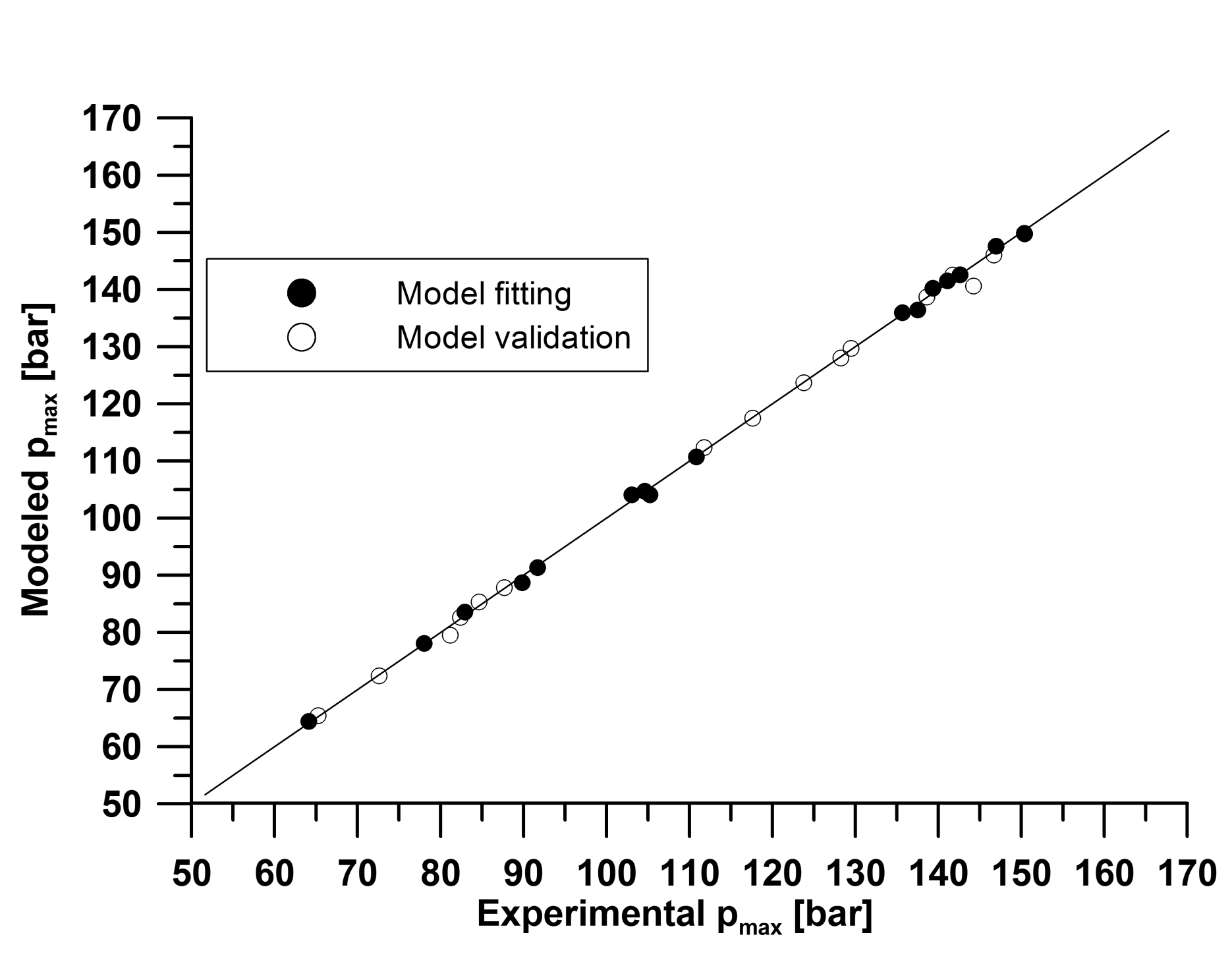

Figure 4 -
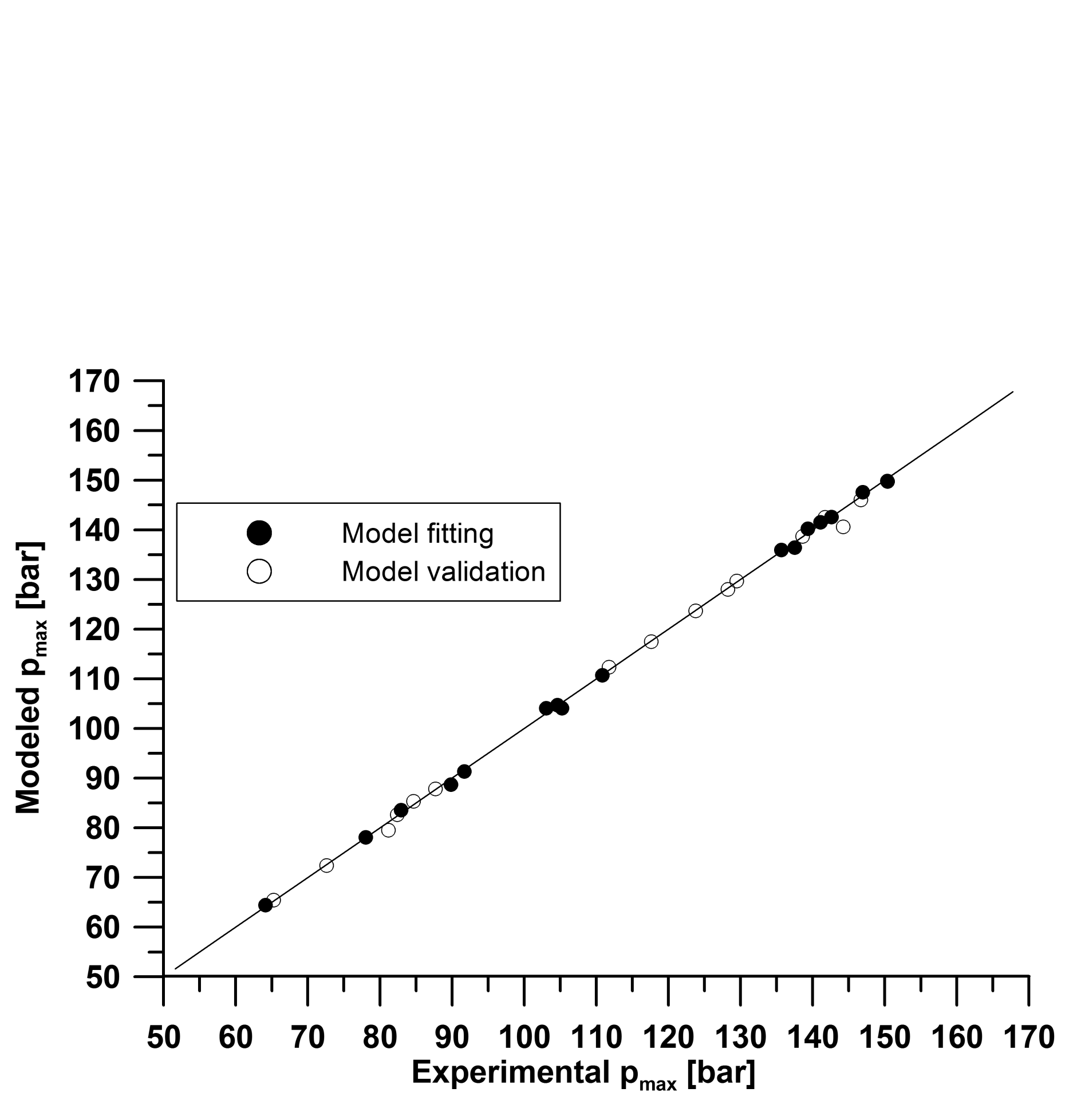
Figure 5

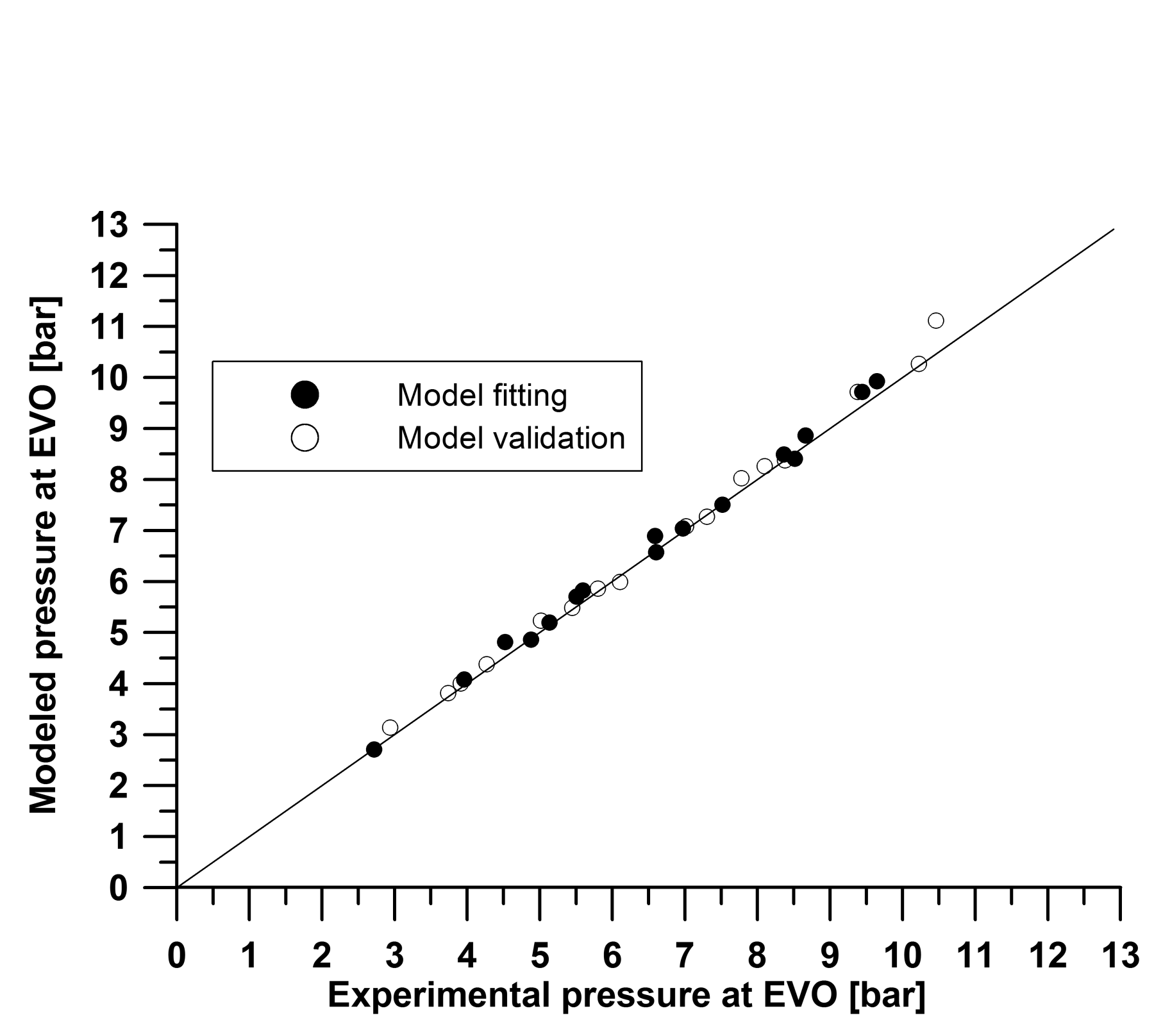

(2n

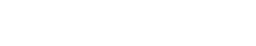
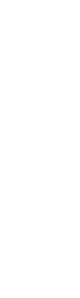

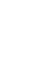

cos
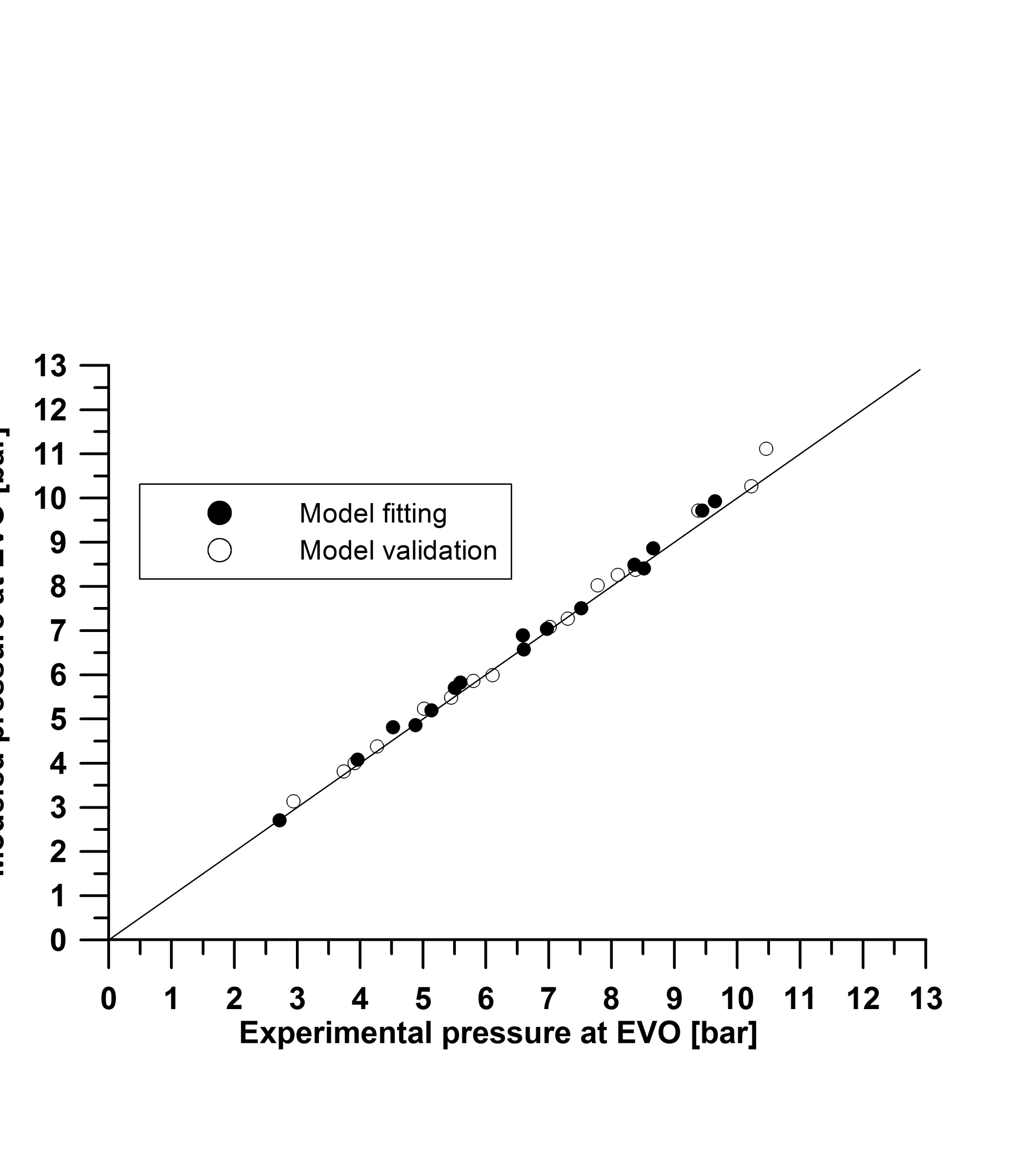

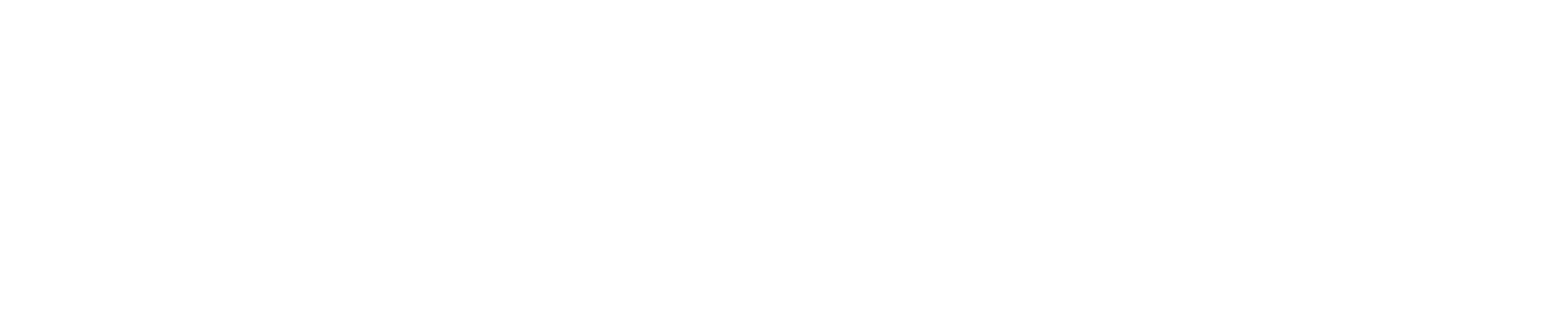

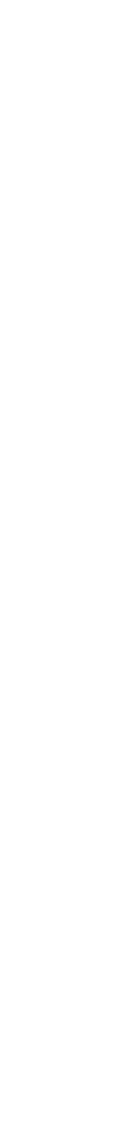




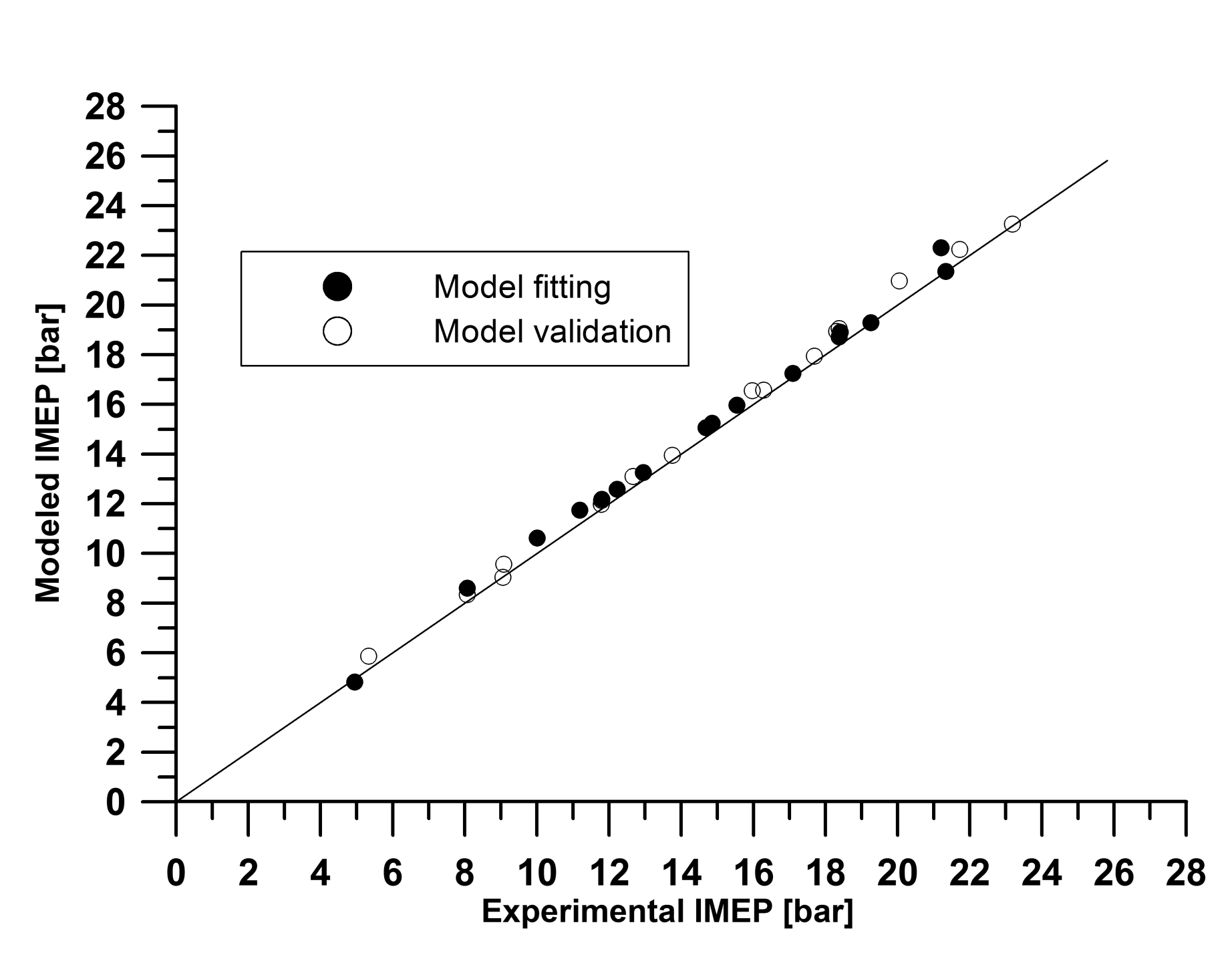

Figure 6

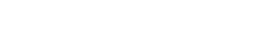

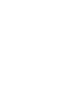

(2)

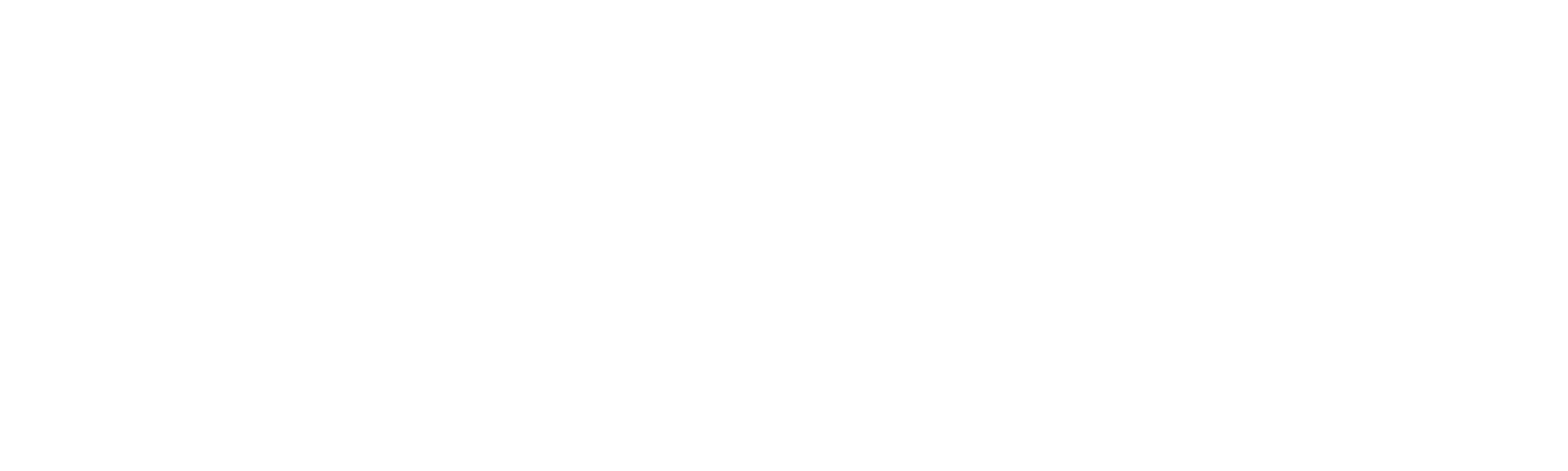

Experimental IMEP [bar]

a
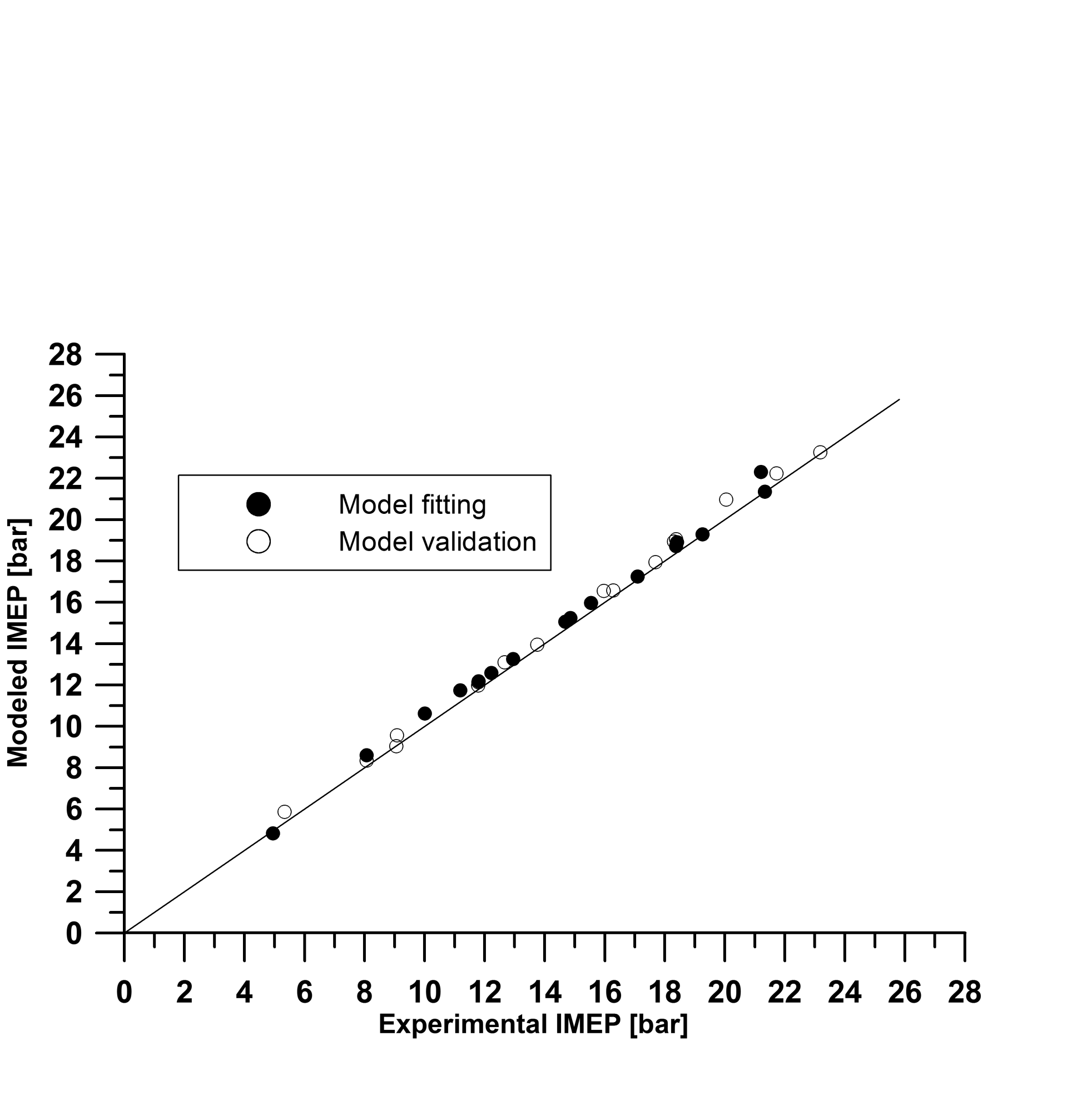
No fuel

sol
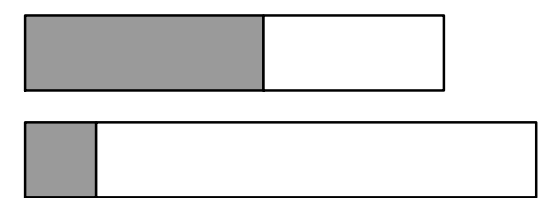

Cw1 \& Cw2

Kdef
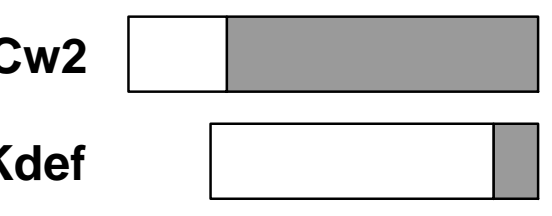

Blow-by

re
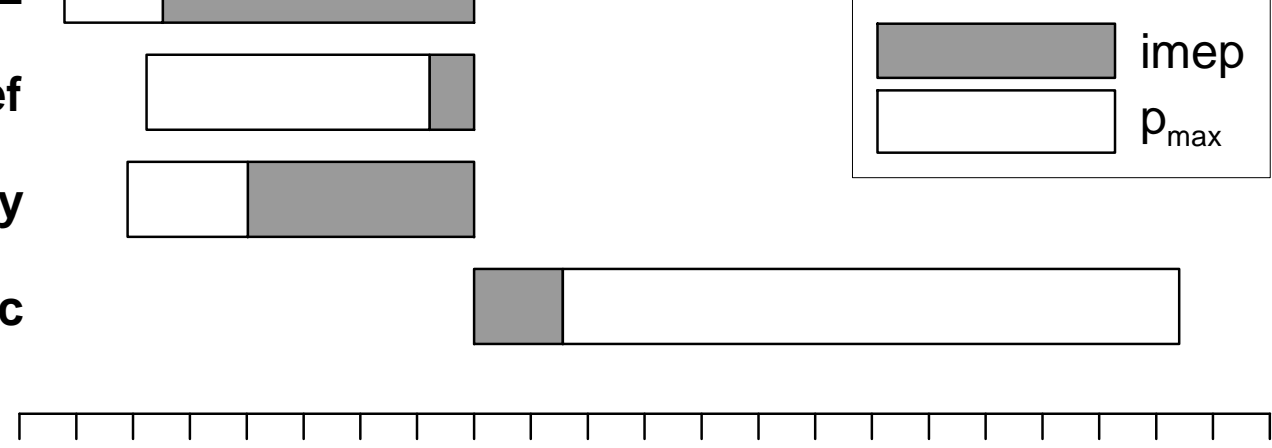

$\begin{array}{llllllllllll}-8 & -6 & -4 & -2 & 0 & 2 & 4 & 6 & 8 & 10 & 12 & 14\end{array}$ imep/ $p_{\max }$ variation [\%] 
Valencia, February 2011

Dear Editor,

Please find enclosed the modified manuscript and figures of our article entitled "Complete 0D thermodynamic predictive model for Direct Injection Diesel engines", by Francisco Payri, Pablo Olmeda, Jaime Martin and Antonio García to be considered for publication in the Journal Applied Energy

In the following pages we have included all the comments made by the reviewers together with our detailed answers to their points.

We hope that the modified version of the paper will be considered worth publishing in your Journal.

Yours sincerely,

Dr. Jaime Martín

jaimardi@mot.upv.es

CMT Motores Térmicos. Universidad Politécnica de Valencia

Valencia, SPAIN E-46022 
Ref: APEN-D-10-01212

Title: complete OD thermodynamic predictive model for Direct Injection Diesel engines

Authors: Francisco Payri, Pablo Olmeda, Jaime Martin and Antonio García

\section{Reviewer \#1:}

First of all, we would like to thank you for your comments. They helped us to address some weak points in the initial manuscript.

In the following paragraphs we try to answer more specifically your comments:

\section{Comments:}

This paper was aimed to develop a 0D thermodynamic model that takes into account the heat transfer, the blow-by leakage, the fuel injection and engine deformations. The objective of this study seems to be rather straightforward. I recommend the authors to have a careful consideration on the points as described below.

1. The author claim the effect of blow-by leakage is considerable in small DI diesel engines (0.35L of displacement), but not important in normal operating conditions. However, the experimental study was carried out in a diesel engine with $2.0 \mathrm{~L}$ of displacement. What is the point of necessity in considering the blow-by leakage?

Extending the information stated in the section "Experimental study: adjustment and validation", the authors would like to underline that the experimental study was carried out in a 4 cylinder high speed direct injection diesel engine with 2.0 liters of total displacement, therefore, the displacement per cylinder is 0.5 liters. Thus the considerations performed in the paper regarding with the importance of blow-by effects on performance in small DI diesel engines is completely applicable in the case of study.

On the other hand, the necessity in considering the blow-by leakage in the 0D model developed is proved with a parametrical study of sensitivity included in section 3.2. As it is shown in the new figure 7, one of the most relevant parameters to predict accurately the Imep in a HSDI is the blow-by. More information related to this topic is answered in the following question.

2. How about the validation of results if the effect of heat transfer, the blow-by leakage, the fuel injection and engine deformations are not individually considered in the OD thermodynamic model? Which is the most important influence? I think the author could further discuss it to show the importance of considering these sub-models.

Taking into account the reviewer comments a short sensitivity study has been included to illustrate the effects of the submodels in comparison with usual engine parameter and operating conditions variations (SOI and compression ratio). This study includes a new table (Table 4) and a new figure (Fig 7) and some explanations in the last paragraphs of section 3.2 Validation of results.

3. The legends of Fig. 1 3 only showed the experimental curve and modeled curve. However, it is not easy to distinguish which curve is related to variation of pressure or rate of heat transfer.

According to the reviewer comment, some arrows have been included in Figs. 1-3 to make easier the differentiation between pressure traces and rate of heat release evolutions. In the authors' opinion the information is now clear, anyway, the editor or reviewer can suggest any additional change if necessary.

4. The description of Fig. 4 6 was not found in manuscript.

There was a mistake in the text at line 400 . In the previous version the text stated: "To illustrate the general behavior of the model, Figs. 1, 2 and 3 show the maximum in-cylinder pressure..." and it should have stated "To illustrate the general behavior of the model, Figs. 4, 5 and 6 show the maximum in-cylinder pressure..." The correction has been done. 
5. I recommend the author to replace some references with recent literature because most references in manuscript were published before year 2007.

Considering the reviewer advice the references have been updated, including several papers published after year 2007:

1. Wang X, Huang Z, Zhang W, Kuti OA, Nishida K. Effects of ultra-high injection pressure and micro-hole nozzle on flame structure and soot formation of impinging diesel spray. Appl Ener 2011;88:1620-1628.

2. Park SH, Yoon SH, Lee CS. Effects of multiple-injection strategies on overall spray behavior, combustion, and emissions reduction characteristics of biodiesel fuel. Appl Ener 2011;88:88-98.

3. Al-Hinti I, Samhouri M, Al-Ghandoor A, Sakhrieh A. The effect of boost pressure on the performance characteristics of a diesel engine: A neuro-fuzzy approach. Appl Ener 2009;86:113-121.

4. Fontana G, Galloni E. Experimental analysis of a spark-ignition engine using exhaust gas recircle at WOT operation. Appl Energy 2010;87:2187-93.

5. Fontana $\mathrm{G}$ and Galloni $\mathrm{E}$. Variable valve timing for fuel economy improvement in a small spark-ignition engine. Appl Energy 2009;86:96-105.

6. Prasad BVVSU, Sharma CS, Anand TNC, Ravikrishna RV. High swirl-inducing piston bowls in small diesel engines for emission reduction. Appl Energy (2011), doi:10.1016/j.apenergy.2010.12.068.

7. Kegl B. Influence of biodiesel on engine combustion and emission characteristics. Appl Energy 2011;88:1803-1812.

8. Al-Hinti I, Akash B, Abu-Nada E, Al-Sarkhi A. Performance analysis of air-standard Diesel cycle using an alternative irreversible heat transfer approach. Energ Convers Manage 2008;49:3301-3304.

9. Sakhrieh A, Abu-Nada E, Al-Hinti I, Al-Ghandoor A, Akash B. Computational thermodynamic analysis of compression ignition engine. Int Commun Heat Mass 2010;37:299-303.

10. Abu-Nada E, Akash B, Al-Hinti I, Al-Sarkhi A. Performance of a spark ignition engine under the effect of friction using a gas mixture model J Energy Inst 2009;82:197-205.

11. Ebrahimi R. Effects of mean piston speed, equivalence ratio and cylinder wall temperature on performance of an Atkinson engine. Mathematical and Computer Modelling 2011;53:1289-1297.

12. Lin JC, Hou SS. Performance analysis of an air-standard Miller cycle with considerations of heat loss as a percentage of fuel's energy, friction and variable specific heats of working fluid. Int J Therm Sci 2008;47:182-191.

13. Y. Ge, L. Chen, F. Sun, Finite-time thermodynamic modeling and analysis for an irreversible dual cycle, Mathematical and Computer Modelling 2009; 50: 101-109.

14. Ozsoysal OA. Effects of combustion efficiency on a Dual cycle. Energ Convers Manage 2009;50:2400-2406.

15. Rakopoulos CD, Kosmadakis GM, Pariotis EG. Critical evaluation of current heat transfer models used in CFD in-cylinder engine simulations and establishment of a comprehensive wall-function formulation. Appl Ener 2010;87:1612-1630.

16. Rakopoulos CD, Kosmadakis GM, Dimaratos AM, Pariotis EG. Investigating the effect of crevice flow on internal combustion engines using a new simple crevice model implemented in a CFD code. Appl Ener 2011;88:111-126.

17. E. Abdi Aghdam and MM Kabir. Validation of a blowby model using experimental results in motoring condition with the change of compression ratio and engine speed. Exp Therm Fluid Sci 2010;34:197-209.

18. Torregrosa AJ, Olmeda P, Martín J, Romero C. A Tool for Predicting the Thermal Performance of a Diesel Engine. Heat Transfer Eng 2011; doi 10.1080/01457632.2011.548639.

19. Torregrosa AJ, Broatch A, Olmeda P, Martín J. A contribution to film coefficient estimation in piston cooling galleries. Exp Therm Fluid Sci 2010;34:142-151. 


\section{Reviewer \#5:}

Thanks for your helpful comments. You suggestions have brought a lot of light to achieve a more complete paper. Let's give you an answer to your different comments

\section{Comments:}

1. There seems many studies in this area as the references listed in the manuscript. I would like to author to clearly address what the major new scientific contributions of this paper compared to previous studies. I also feel author shall update the research literature to give the most recent results in this area.

In the introduction, the following sentence has been changed accordingly to this comment:

"The objective of the present work is to develop a 0D single-zone thermodynamic model covering all the previous statements (the simulation of the rate of heat release law, heat transfer and gas properties sub-models as well as blow-by leakage and the fuel injection contributions to the diesel engine cycles) that have been partially covered by previous researchers."

The references has been updated (see answer to question 5).

2. A comparison of the method in this paper to other performance evaluation of a engine shall be discussed. In particular, it needs further address how this method can be applied in the real application?

The reviewer consideration is well addressed; however, the authors would like to underline that in sub-section 3.2 the model presented in the paper is validated versus experimental

measurements derived from an in-cylinder pressure sensor. Specifically, in figures 1, 2 and 3 is possible to prove how is the temporal evolution of in-cylinder pressure and heat release for three very different engine operating conditions. Thus, as is stated in the paper, the agreement between measured and predicted cylinder traces is good and therefore, in a first stage, the applicability of the developed model in real engine conditions is shown.

Continuing with the answer and with the aim of better illustrating the general and real behavior of the model, in figures 4, 5 and 6 are shown the maximum in-cylinder pressure, the pressure at exhaust valve opening and the indicated mean effective pressure for all operating points used for both the model adjustment and model validation. Once again, considering these parameters, the accuracy of the model in real conditions is proved. 